\title{
A theoretical approach to assess soil moisture-climate coupling across CMIP5 and GLACE-CMIP5 experiments
}

\author{
Clemens Schwingshackl, Martin Hirschi, and Sonia I. Seneviratne \\ Institute for Atmospheric and Climate Science, ETH Zürich, Universitätsstrasse 16, 8092 Zürich, Switzerland \\ Correspondence: Clemens Schwingshackl (clemens.schwingshackl@env.ethz.ch)
}

Received: 25 May 2018 - Discussion started: ESDD 7 June

Accepted: 17 September 2018 - Published: 17 October 2018

\begin{abstract}
Terrestrial climate is influenced by various land-atmosphere interactions that involve numerous land surface state variables. In several regions on Earth, soil moisture plays an important role for climate via its control on the partitioning of net radiation into sensible and latent heat fluxes; consequently, soil moisture also impacts on temperature and precipitation. The Global Land-Atmosphere Coupling Experiment-Coupled Model Intercomparison Project phase 5 (GLACE-CMIP5) aims to quantify the impact of soil moisture on these important climate variables and to trace the individual coupling mechanisms. GLACE-CMIP5 provides experiments with different soil moisture prescriptions that can be used to isolate the effect of soil moisture on climate. Using a theoretical framework that relies on the distinct relation of soil moisture with evaporative fraction (the ratio of latent heat flux over net radiation) in different soil moisture regimes, the climate impact of the soil moisture prescriptions in the GLACE-CMIP5 experiments can be emulated and quantified. The framework-based estimation of the soil moisture effect on the evaporative fraction agrees very well with estimations obtained directly from the GLACE-CMIP5 experiments (pattern correlation of 0.85). Moreover, the soil moisture effect on the daily maximum temperature is well captured in regions where soil moisture exerts a strong control on latent heat fluxes. The theoretical approach is further applied to quantify the soil moisture contribution to the projected change of the temperature on the hottest day of the year, confirming recent estimations by other studies. Finally, GLACE-style soil moisture prescriptions are emulated in an extended set of CMIP5 models. The results indicate consistency between the soil moisture-climate coupling strength estimated with the GLACE-CMIP5 and the CMIP5 models. Although the theoretical approach is only designed to capture the local soil moisture-climate coupling strength, it can also help to distinguish non-local from local soil moisture-atmosphere feedbacks where sensitivity experiments (such as GLACE-CMIP5) are available. Overall, the theoretical framework-based approach presented here constitutes a simple and powerful tool to quantify local soil moisture-climate coupling in both the GLACE-CMIP5 and CMIP5 models that can be applied in the absence of dedicated sensitivity experiments.
\end{abstract}

\section{Introduction}

The amount of available energy at the surface is a key driver for climate on Earth. It provides a first-order control on the location of the different climate zones and is an important contributor to weather and climate variations at daily, seasonal, and longer-term timescales. Absorbed shortwave and net longwave radiation at the surface constitute the inputs for the available energy, the so called net radiation. This energy is used for the evaporation and transpiration of water from soils and plants, it is transported as heat to the atmosphere, and it warms up the soil. The partitioning of the net radiation into these latent, sensible, and ground heat fluxes is of fundamental importance for the investigation of climate, as the shares of the single fluxes influence various basic climate variables such as temperature, precipitation, and atmospheric humidity.

In several regions of the world, soil moisture impacts the partitioning of the net radiation by exerting control on latent heat flux (Koster et al., 2004; Seneviratne et al., 2010). Nu- 
merous studies have analyzed the coupling strength between soil moisture and latent heat flux and have tried to identify the regions where soil moisture influences atmospheric conditions and, in turn, the climate. Using the correlation between evapotranspiration and radiation and contrasting it to the correlation between evapotranspiration and precipitation, Teuling et al. (2009) identified regions with either radiation or soil moisture control on latent heat flux. Dirmeyer (2011) introduced a metric that combines the sensitivity of latent heat flux to soil moisture changes with typical soil moisture variations and quantified the coupling strength therewith. Koster et al. (2009) used an idealized framework for describing the relation between soil moisture and the evaporative fraction (the share of net radiation going into latent heat flux) which makes it possible to distinguish between different soil moisture regimes (Koster et al., 2009; Seneviratne et al., 2010).

Other metrics focus on the impact of soil moisture changes on atmospheric variables. Koster et al. (2004) used the precipitation based $\Omega_{\mathrm{P}}$-metric (introduced by Koster et al., 2000) to quantify the impact of soil moisture on precipitation. Adapting this measure to investigate the effect of soil moisture on temperature, Seneviratne et al. (2006) showed the importance of land-atmosphere coupling for future summer temperature projections in Europe. Soil moisturetemperature coupling was further examined by Miralles et al. (2012) who established the П-metric, which is based on the correlation of (potential) sensible heat flux and temperature. Miralles et al. (2012) used this measure to identify regions with strong soil moisture effects on temperature. Zscheischler et al. (2015) introduced the vegetation-atmosphere coupling index (VAC) that can serve as proxy for estimating the coupling strength between soil moisture and latent heat flux. This index was used by Sippel et al. (2017) to diagnose land-atmosphere coupling in climate models, reanalyses, and observation-based datasets. Their results indicate an overestimation of land-atmosphere coupling in models participating in the Coupled Model Intercomparison Project phase 5 (CMIP5). Other approaches used to diagnose landatmosphere interactions incorporate wavelet correlation analysis (Casagrande et al., 2015) or consider processes in the atmospheric boundary layer to reflect the full land-atmosphere coupling chain (Santanello et al., 2011, 2015; Miralles et al., 2014).

Through its control on the partitioning of the net radiation into latent and sensible heat fluxes, soil moisture can have a pronounced impact on near-surface air temperature (Seneviratne et al., 2010; Miralles et al., 2012; Hirschi et al., 2014; Schwingshackl et al., 2017). Particularly during droughts and heat waves the impact of soil moisture on temperature can become very strong. Using the standardized precipitation index (SPI) as a proxy for soil moisture, Hirschi et al. (2011) and Mueller and Seneviratne (2012) showed that the number of heat wave days in the hottest month of the year depends on preceding moisture conditions in transitional climate regimes. Moreover, soil moisture and the yearly max- imum value of daily maximum temperature $\left(\mathrm{TX}_{x}\right)$ exhibit a negative linear relationship in Europe (Whan et al., 2015), emphasizing the strong relation between soil moisture and temperature extremes. Miralles et al. (2014) highlighted the importance of both soil moisture-temperature coupling and boundary layer feedbacks for the evolution of the 2003 European heat wave and the 2010 heat wave in Russia. Performing modeling experiments, Hauser et al. (2016) showed that extreme soil moisture conditions such as those observed during the 2010 Russian heat wave strongly contribute to the increased risk of similar events.

The study of soil moisture-climate coupling is often limited by the sparse availability of soil moisture observations. In situ measurements are relatively rare and are restricted to a few regions (Seneviratne et al., 2010; Dorigo et al., 2011). For global studies, an alternative approach consists of using satellite-based soil moisture estimates. While satellites provide quasi-global coverage, data availability is poor in regions with dense vegetation cover; furthermore, reliable soil moisture measurements are only available since the 1990s (de Jeu et al., 2008; Dorigo et al., 2017). Moreover, remote sensing can only provide surface soil moisture - no direct root zone soil moisture estimations are available.

As a consequence of these limitations for the use of observations, model simulations have been widely employed to investigate the impact of soil moisture on atmospheric conditions and climate. For example, the Global LandAtmosphere Coupling Experiments (GLACE-1 and GLACE2; Koster et al., 2006, 2010; van den Hurk et al., 2011) were used to investigate soil moisture-precipitation and soil moisture-temperature coupling on seasonal timescales. For studying long-term effects, these experiments were further extended to include several CMIP5 models (GLACECMIP5; Seneviratne et al., 2013). GLACE-CMIP5 was extensively used to investigate various features of landatmosphere coupling. Berg et al. (2014) analyzed soil moisture-atmosphere interactions, in particular their effect on temperature, in GFDL (Geophysical Fluid Dynamics Laboratory) Earth system model simulations that contributed to GLACE-CMIP5. Lorenz et al. (2015) performed GLACE1 and GLACE-CMIP5 experiments with the ACCESS1.3b model and applied several land-atmosphere coupling measures to investigate the impact of soil moisture on atmospheric conditions in the different soil moisture experiments. Berg et al. (2015) investigated terrestrial and atmospheric contributions to the correlation between temperature and precipitation using the GLACE-CMIP5 experiments. Moreover, soil moisture trends and land-atmosphere feedbacks were found to contribute to a future increase in aridity (Berg et al., 2016) and to be important for explaining future temperature and precipitation changes in the tropics (May et al., 2015).

Additionally, GLACE-CMIP5 models were used to study the impact of soil moisture on extremes. Lorenz et al. (2016) highlighted the effect of soil moisture on both temperature and precipitation extremes. However, they also found that the 
large variability of soil moisture trends in the single GLACECMIP5 models leads to large uncertainties for projections of future climate extremes. Recently, Vogel et al. (2017) showed that the soil moisture prescription in the different GLACECMIP5 experiments has a strong impact on $\mathrm{TX}_{x}$ with higher $\mathrm{TX}_{x}$ values occurring at lower soil moisture contents.

Thus, GLACE-CMIP5 simulations provide a rich source for examining soil moisture-climate coupling. Moreover, the fact that the single simulations only differ from each other regarding the way soil moisture is prescribed, makes it possible to attribute emerging differences to soil moisture shifts. Here we present a theoretical approach to quantify the effect that the different soil moisture prescriptions in the various GLACE-CMIP5 experiments have on the evaporative faction (EF) and the daily maximum near-surface air temperature (TX). The approach, which was introduced and validated by Schwingshackl et al. (2017), is based on the distinct impact of soil moisture $(\theta)$ on EF and TX in different soil moisture regimes (see Sect. 2). A major advantage of this theoretical approach is that it enables researchers to emulate GLACEstyle soil moisture prescription. In particular, it can be directly applied to CMIP5 models without the need for performing additional model simulations. We use this approach to investigate how soil moisture shifts across the GLACECMIP5 experiments influence EF and TX. In addition, the resulting relationships are applied to estimate the soil moisture contribution to $\mathrm{TX}_{x}$ and are also compared to the estimations from Vogel et al. (2017).

\section{Theoretical background: $\operatorname{EF}(\theta)$ framework}

Soil moisture can have an impact on the exchange of water and energy between the land and the atmosphere via its control on latent heat flux. This relationship can be specified using a simple framework that connects EF to soil moisture (Koster et al., 2009; Seneviratne et al., 2010). The framework, illustrated in Fig. 1a, distinguishes between three different soil moisture regimes: (1) the wet soil moisture regime where EF is independent of soil moisture, (2) the transitional regime in which EF and soil moisture are linearly coupled, and (3) the dry regime in which EF is zero. Schwingshackl et al. (2017) show the applicability of this framework to describe spatiotemporal variations of the $\operatorname{EF}(\theta)$ relationship for several datasets and use the resulting $\operatorname{EF}(\theta)$ curve to classify the different soil moisture regimes. They further employ the framework to analyze the effect of soil moisture variations on the surface energy balance and TX individually in the different regimes.

Based on tenfold cross validation, their methodology first selects the best curve for describing $\operatorname{EF}(\theta)$ from a pool of possible, preselected functions for each grid point separately. The obtained functional relationship is then used to estimate the two soil moisture values that separate the three regimes: the wilting point $\left(\theta_{\text {wilt }}\right)$, separating dry and transi- tional regimes, and the critical point $\left(\theta_{\text {crit }}\right)$, separating the transitional and wet regimes. This allows for the unique attribution of each daily soil moisture value to one soil moisture regime and for the analysis of the effect of soil moisture variations on atmospheric conditions in each regime individually.

Using this approach, the sensitivity of EF to soil moisture variations (i.e., the gradient $\partial \mathrm{EF} / \partial \theta$ ) can be estimated in the different soil moisture regimes separately. (Note that although the $\operatorname{EF}(\theta)$ framework requires a constant line in the wet regime, the actual fitting routine optimizes the location of the wilting and critical points. As a result, when calculating $\partial \mathrm{EF} / \partial \theta$ from the daily $\mathrm{EF}$ and soil moisture estimates, the slope in the wet regime is small, but not necessarily identical to zero). Similarly, the sensitivity of TX to soil moisture changes can be quantified in each regime. The sensitivity is expected to differ between the soil moisture regimes due to the distinct impact of soil moisture on the partitioning of the net radiation into latent and sensible heat fluxes in each of the regimes. The gradient $\partial \mathrm{TX} / \partial \theta$ is strongest in the transitional regime, in which soil moisture has an impact on EF, while in the dry and wet regimes the impact of soil moisture on TX is small (Schwingshackl et al., 2017). Whenever the soil moisture content crosses the regime borders, the soil moisture effect on EF and TX is a mixture of the sensitivities in the different soil moisture regimes.

This theoretical approach can easily be applied to quantify the effect of soil moisture variations on EF and TX based on the distinct sensitivities in the different soil moisture regimes. In the present study the approach is used to theoretically quantify the effect that soil moisture shifts across different GLACE-CMIP5 experiments (see Sect. 3.1.1 for details) have on EF and TX. To distinguish direct and indirect soil moisture effects on EF and TX the theoretical framework-based estimations are compared and contrasted to direct estimations of the coupling strength based on the GLACE-CMIP5 experiments. The (dis)agreement between the framework- and experiment-based estimations provide an indication of whether soil moisture affects EF and TX directly through its control on the partitioning of the net radiation into latent and sensible heat fluxes or if the coupling involves secondary effects. The following methods section explains the detailed derivation of both measures as well as their application to quantify soil moisture-climate coupling in both CMIP5 and GLACE-CMIP5.

\section{Methods and Data}

\subsection{Data}

\subsubsection{GLACE-CMIP5}

Direct estimations of the coupling strength between different Earth system variables are often challenging due to the system's complex feedback structures. One option to tackle this issue is to employ idealized climate modeling experiments. 

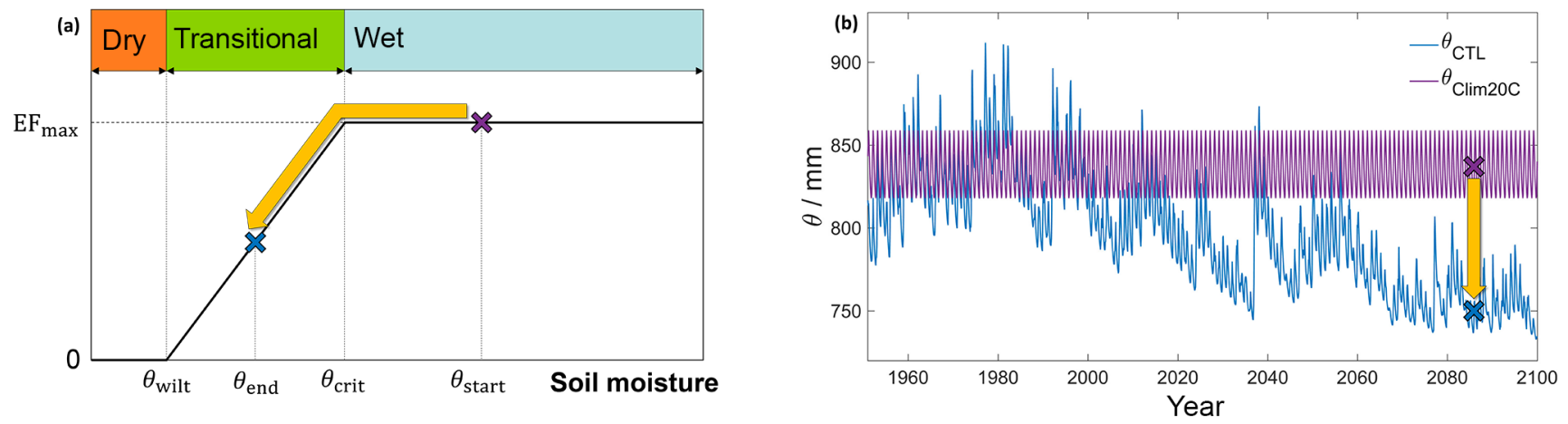

Figure 1. (a) Conceptual framework for the dependence of the evaporative fraction (EF) on soil moisture $(\theta)$ and the classification of the different soil moisture regimes (adapted from Seneviratne et al., 2010). $\theta_{\text {wilt }}$ is the wilting point and $\theta_{\text {crit }}$ is the critical point. (b) An example of soil moisture evolution in the GLACE-CMIP5 control run $\left(\theta_{\mathrm{CTL}}\right)$ and the run with prescribed 1971-2000 soil moisture climatology $\left(\theta_{\mathrm{Clim} 20 \mathrm{C}}\right)$ in EC-EARTH at a grid point close to Jerusalem. For illustration purposes, two soil moisture values (shown as violet and blue crosses) representing soil moisture values in $\theta_{\mathrm{CTL}}$ and $\theta_{\mathrm{Clim} 20 \mathrm{C}}$ are indicated. The shift in soil moisture between the experiments could potentially lead to a change in soil moisture regimes (yellow arrow in a) and, in turn, to a nonlinear change in EF.

GLACE-CMIP5 (Seneviratne et al., 2013) investigates the question regarding the extent to which soil moisture influences climate due to its impact on land-atmosphere coupling. GLACE-CMIP5, for which six CMIP5 modeling groups contributed the necessary model runs, includes three soil moisture experiments:

- CTL: a control run with interactive soil moisture and prescribed sea surface temperatures, sea ice, land use, and atmospheric $\mathrm{CO}_{2}$ concentrations from the respective CMIP5 historical and Representative Concentration Pathway 8.5 (RCP8.5; Riahi et al., 2011) simulations.

- Clim20C: a model run with soil moisture prescribed as 1971-2000 climatology of the control run ("EXP A", here referred to as Clim20C).

- ClimCTL: a model run with soil moisture prescribed as transient climatology of the control run ("EXP B", here referred to as ClimCTL).

An example of the soil moisture evolution in the different experiments is shown in Fig. 1b for CTL and Clim20C and in Fig. S1 for CTL and ClimCTL. While ClimCTL is aimed at eliminating the (short-term) interannual soil moisture variability, in Clim20C long-term soil moisture trends are additionally removed.

Four out of the six available GLACE-CMIP5 models provide all of the necessary daily data for the analyses performed in this study. These models are ACCESS, EC-EARTH, GFDL's ESM2M, and MPI-ESM-LR (see Table S1). The soil moisture prescription in ACCESS Clim20C has a known issue, namely a shift of the seasonal cycle between 2039/40 and 2089/90 (Ruth Lorenz, ETH Zürich, personal communication, 2017). However, as we rely on our own recomputed soil moisture climatologies (see Figs. 1b and S1) for the the- oretical approach, this shift should not affect the estimated effects.

\subsubsection{CMIP5}

In addition to the GLACE-CMIP5 runs, the output of 20 CMIP5 models (Taylor et al., 2012) from historical simulations and the RCP8.5 scenario is used. The models are selected based on the availability of the daily data that are necessary for performing the analyses. A list with all the CMIP5 models that were used can be found in Table S1.

While the analyses presented here use total column soil moisture, the CMIP5 model standard output only provides daily data for soil moisture in the top soil layer. For total column soil moisture only monthly data are available. Therefore, daily total column soil moisture $(\theta)$ is reconstructed using the water balance equation:

$\theta(t+1)=\theta(t)+P(t)-\mathrm{ET}(t)-R(t)-\Delta h_{\text {snow }}$,

where $P$ is precipitation, ET is evapotranspiration, $R$ is total runoff, and $\Delta h_{\text {snow }}$ is the change of surface snow (in water equivalent) between time steps (days) $t$ and $t+1$. The starting value $\theta(t=0)$ can be chosen arbitrarily because for the analyses applied here only soil moisture variability and trends are relevant. The reconstructed time series spans the period from 1950 to 2100 . Note that we do not consider the canopy reservoir as it is usually small. However, in regions with dense vegetation and shallow soils it might introduce some uncertainty in Eq. (1).

To remove any artificial drifts imposed by Eq. (1), the reconstructed daily total column soil moisture estimates are linearly detrended on each grid box individually. In addition, the multi-year variability of the reconstructed time series is adjusted to match the variability of the monthly soil 
moisture data that are available in the CMIP5 archive: first, we subtract the 3-year running mean from the reconstructed daily data; we then add back the 3-year running mean of the monthly CMIP5 soil moisture values (which are interpolated to daily values by cubic spline) to the reconstructed soil moisture series. To reaffirm that these corrected daily soil moisture values are in agreement with the CMIP5 soil moisture, monthly means of the corrected daily soil moisture values are compared to the CMIP5 monthly soil moisture content. We require that the correlation between both estimates over the whole period from 1950 to 2100 is higher than 0.99 and that the root mean squared error is smaller than $10 \%$ of the standard deviation of the monthly CMIP5 soil moisture. Grid points where these criteria are not met are not considered in the analyses in the respective model. A map with the final number of CMIP5 models considered at each grid cell is shown in Fig. S2.

\subsubsection{Data preparation}

Soil moisture effects on climate are examined using two different measures. The experiment-based effect is obtained directly from the GLACE-CMIP5 experiments, while the framework-based effect is based on the distinct relation between EF and soil moisture (and TX and soil moisture) in the different soil moisture regimes of the $\operatorname{EF}(\theta)$ framework. As the latter relies on theoretical calculations of soil moistureclimate coupling, it can be applied to both GLACE-CMIP5 and CMIP5 to emulate Clim20C and ClimCTL (see Sect. 3.2 and 3.3 for more details about the derivation of the measures).

For each model of GLACE-CMIP5 and CMIP5, the methodology of Schwingshackl et al. (2017) is applied to identify the different soil moisture regimes, which are required to calculate the framework-based effect. The $\operatorname{EF}(\theta)$ relationships and the soil moisture regime classifications (see Sect. 2) are obtained with data from the control run only. Daily data for total column soil moisture (calculated with Eq. 1 for the CMIP5 models), latent heat flux, sensible heat flux, net radiation, and daily maximum near-surface air temperature are used. Following the procedure of Berg et al. (2017), soil moisture data are normalized by the standard deviation of all daily soil moisture values of the control run in the reference period from 1970 to 1999 on each grid point separately for each model individually before performing the analyses. Following the methodology of Schwingshackl et al. (2017), the experiment- and framework-based effects (see Sect. 3.2 and 3.3) are estimated for 12 different 3-month subsets individually (i.e., all data from JanuaryMarch, February-April,... December-February in the respective time period are pooled separately) and then averaged. The number of 3-month subsets on a grid point might be less than 12 since we require that all variables involved in calculating EF are positive (see Schwingshackl et al., 2017 for details).
By calculating the framework-based effect, GLACE-style soil moisture prescriptions can be theoretically emulated with CMIP5 models (see Sect. 3.2 and 3.3). For this purpose, soil moisture values equivalent to those in Clim20C and ClimCTL of GLACE-CMIP5 (see Figs. 1b and S1) are calculated for all CMIP5 models using the reconstructed daily total column soil moisture estimates and following the procedure for calculating prescribed soil moisture in the different GLACE-CMIP5 experiments (Seneviratne et al., 2013). Similarly, $\theta_{\text {Clim20C }}$ and $\theta_{\text {ClimCTL }}$ are also calculated for the GLACE-CMIP5 models. By combining these soil moisture estimates with the distinct sensitivities of EF to soil moisture in the single soil moisture regimes the framework-based effect can be estimated (see Sect. 3.2).

The analysis is performed for the time span from 2070 to 2099 on each grid point individually. In addition, for investigating the effect of soil moisture on the yearly maximum value of the daily maximum temperature $\left(\mathrm{TX}_{x}\right)$ five different time periods are used. These time periods are selected based on the model-dependent year when global mean temperature increase $\Delta T_{\text {glob }}$ reaches $1.0,1.5,2.0,2.5$, and $3.0 \mathrm{~K}$ above preindustrial temperature levels. To be consistent with the GLACE-CMIP5 simulations, which only start in 1951, 1951-1970 was chosen as the reference period for $\Delta T_{\text {glob }}$ and $0.22 \mathrm{~K}$ is added to account for the $T_{\text {glob }}$ increase that occurred between 1871-1890 and 1951-1970 according to the 20 CMIP5 models used in this study. $\Delta T_{\text {glob }}$ is smoothed with a 20-year window to eliminate short-term variations in order to uniquely identify the year in which $\Delta T_{\text {glob }}$ reaches $1.0,1.5,2.0,2.5$, and $3.0 \mathrm{~K}$. The analysis is then performed considering data from a 20-year window centered around the selected year. $\mathrm{TX}_{x}$ changes (i.e., $\Delta \mathrm{TX}_{x}$ ) are also based on the reference period from 1951 to 1970 (calculated on each grid point individually and for GLACE-CMIP5 in each experiment separately). To be consistent with the methodology for $T_{\mathrm{glob}}$ and to start from the same level, an offset of $0.22 \mathrm{~K}$ is added as well.

The effect of soil moisture prescription on $\mathrm{TX}_{x}$ is analyzed for several regions that are known to have strong soil moisture-climate coupling. The regions considered correspond to areas defined in the "Special Report on Managing the Risks of Extreme Events and Disasters to Advance Climate Change Adaptation" (SREX; Seneviratne et al., 2012).

\subsection{Estimating the soil moisture effect on the evaporative fraction}

For the GLACE-CMIP5 models, the output of the three experiments CTL, Clim20C, and ClimCTL can be used to directly estimate the "experiment-based" effect of the different soil moisture prescriptions on EF. For this purpose, the daily differences of soil moisture $\Delta \theta$ and the evaporative fraction $\Delta \mathrm{EF}$ are calculated across experiments and the average sensitivity of $\mathrm{EF}$ to soil moisture shifts (i.e., $\Delta \mathrm{EF} / \Delta \theta$ ) is quan- 
tified from the slope of a linear fit between $\Delta \theta$ and $\Delta \mathrm{EF}$ (without allowing for a constant term).

In addition, $\Delta \mathrm{EF} / \Delta \theta$ estimates can be reproduced considering the three different soil moisture regimes according to the $\operatorname{EF}(\theta)$ framework and the distinct sensitivities $\partial \mathrm{EF} / \partial \theta$ within them (Fig. 1a). When soil moisture changes across regime limits, the average effect on EF can be assumed to be a mixing of the sensitivities in the respective regimes:

$$
\frac{\Delta \mathrm{EF}}{\Delta \theta}=\left.\frac{\theta_{\text {start }}-\theta_{\text {crit }}}{\theta_{\text {start }}-\theta_{\text {end }}} \frac{\partial \mathrm{EF}}{\partial \theta}\right|_{\text {wet }}+\left.\frac{\theta_{\text {crit }}-\theta_{\text {end }}}{\theta_{\text {start }}-\theta_{\text {end }}} \frac{\partial \mathrm{EF}}{\partial \theta}\right|_{\text {trans }},
$$

where the subscript wet and trans indicate the wet and transitional regimes, respectively, and $\theta_{\text {start }}$ and $\theta_{\text {end }}$ are the start and end soil moisture values. Whenever $\theta_{\text {start }}$ and $\theta_{\text {end }}$ are in the same soil moisture regime, $\Delta \mathrm{EF} / \Delta \theta$ is simply taken as the sensitivity $\partial \mathrm{EF} / \partial \theta$ in the respective regime. Moreover, we enforce that $\theta_{\text {end }}$ can not be lower than $\theta_{\text {wilt }}$ since EF is zero below the wilting point.

$\Delta \mathrm{EF} / \Delta \theta$ is calculated for the difference between the soil moisture experiments CTL and Clim20C and for the difference between CTL and ClimCTL. $\theta_{\text {start }}$ and $\theta_{\text {end }}$ represent soil moisture values in two different experiments (e.g., $\theta_{\text {start }}$ in Clim20C and $\theta_{\text {end }}$ in CTL, as illustrated in Fig. 1). The difference in EF is then calculated as a theoretical passage between $\theta_{\text {start }}$ and $\theta_{\text {end }}$ according to the $\operatorname{EF}(\theta)$ curve. The term $\Delta \mathrm{EF} / \Delta \theta$ is computed for each day of the investigated time period (either 20-years or 30-years long, see Sect. 3.1.3) and averaged across all daily estimates. The averaged $\Delta \mathrm{EF} / \Delta \theta$ estimate represents the "framework-based" sensitivity of EF to soil moisture.

Multiplying $\Delta \mathrm{EF} / \Delta \theta$ by the mean soil moisture shift between the investigated experiments yields the measure $\delta \mathrm{EF}_{\theta}$ that represents the absolute response of EF to the mean soil moisture shifts between the experiments.

The calculation of the framework-based measures only requires input data from the CTL experiment. Thus, in addition to the GLACE-CMIP5 models, it can be applied to CMIP5 model output, which represents the CTL experiment in this case. This allows one to theoretically reproduce the GLACECMIP5 soil moisture experiments with all 20 CMIP5 models that provide the necessary (daily) data for calculating the framework-based estimates of soil moisture-climate coupling.

\subsection{Estimating the soil moisture effect on temperature}

\subsubsection{Effect on daily maximum temperature}

Due to the distinct impact of soil moisture on the magnitude of latent and sensible heat fluxes in the different soil moisture regimes, $\partial \mathrm{TX} / \partial \theta$ is also expected to take different values in the single regimes. To quantify the effect that soil moisture shifts across the different experiments have on TX, an analogous calculation as in Eq. (2) can thus be applied, using
TX instead of EF and considering the distinct sensitivities $\partial \mathrm{TX} / \partial \theta$ in the single soil moisture regimes:

$$
\frac{\Delta \mathrm{TX}}{\Delta \theta}=\left.\frac{\theta_{\text {start }}-\theta_{\text {crit }}}{\theta_{\text {start }}-\theta_{\text {end }}} \frac{\partial \mathrm{TX}}{\partial \theta}\right|_{\text {wet }}+\left.\frac{\theta_{\text {crit }}-\theta_{\text {end }}}{\theta_{\text {start }}-\theta_{\text {end }}} \frac{\partial \mathrm{TX}}{\partial \theta}\right|_{\text {trans }} .
$$

Again, soil moisture and TX data are only used from CTL; thus, the approach can be applied to CMIP5 data as well. For the GLACE-CMIP5 models the effect can also be directly estimated from the different model experiments by performing a linear fit between the soil moisture and TX differences across the experiments, analogous to the experiment-based estimation of the soil moisture effect on EF. Multiplying $\Delta \mathrm{TX} / \Delta \theta$ by the mean soil moisture shift between the investigated experiments yields the average TX response to the soil moisture shift (denoted $\delta \mathrm{TX}_{\theta}$ ). In addition, we estimate the effect that shifts between the lowermost (first) percentile of the soil moisture distribution in the investigated experiments have on TX (denoted as $\left.\delta \mathrm{TX}_{\theta_{\mathrm{Q} 1}}\right)$.

\subsubsection{Effect on $\mathrm{TX}_{X}$}

The framework-based estimates can also be used to quantify the contribution of soil moisture to the projected changes of $\mathrm{TX}_{x}$. For this purpose we first identify the day on which $\mathrm{TX}_{x}$ occurs for each year and each grid point individually. Subsequently, the framework-based soil moisture effect on TX is calculated by applying Eq. (3), using the sensitivity $\partial \mathrm{TX} / \partial \theta$ from the 3-month subset that is centered on the month in which $\mathrm{TX}_{x}$ occurs and the soil moisture values in CTL and Clim20C (or CTL and ClimCTL) on the day on which $\mathrm{TX}_{x}$ occurs. Multiplying the $\Delta \mathrm{TX} / \Delta \theta$ estimate by the soil moisture shift between the two experiments on that day results in the theoretical soil moisture effect on $\mathrm{TX}_{x}$. This procedure is performed individually for all years considered (that is, the 20 years surrounding a certain $\Delta T_{\text {glob }}$ ), yielding 20 estimates, of which the mean is taken to get the average contribution. By subtracting these framework-based $\mathrm{TX}_{x}$ contributions from $\Delta \mathrm{TX}_{x}$ in CTL, it is possible to estimate the theoretical $\Delta \mathrm{TX}_{x}$ in Clim20C (and accordingly in ClimCTL). Moreover, for the GLACE-CMIP5 models these estimates can be compared to $\Delta \mathrm{TX}_{x}$ directly estimated from the Clim20C and ClimCTL experiments.

\section{Results}

Here and in the following we focus on the difference between the CTL and Clim20C experiments. The results when CTL and ClimCTL are considered instead can be found in the Supplement.

\subsection{Occurrence of soil moisture regimes}

The multimodel mean temporal share of the different soil moisture regimes (based on the twelve 3-month subsets) for 
Dry regime

Transitional regime
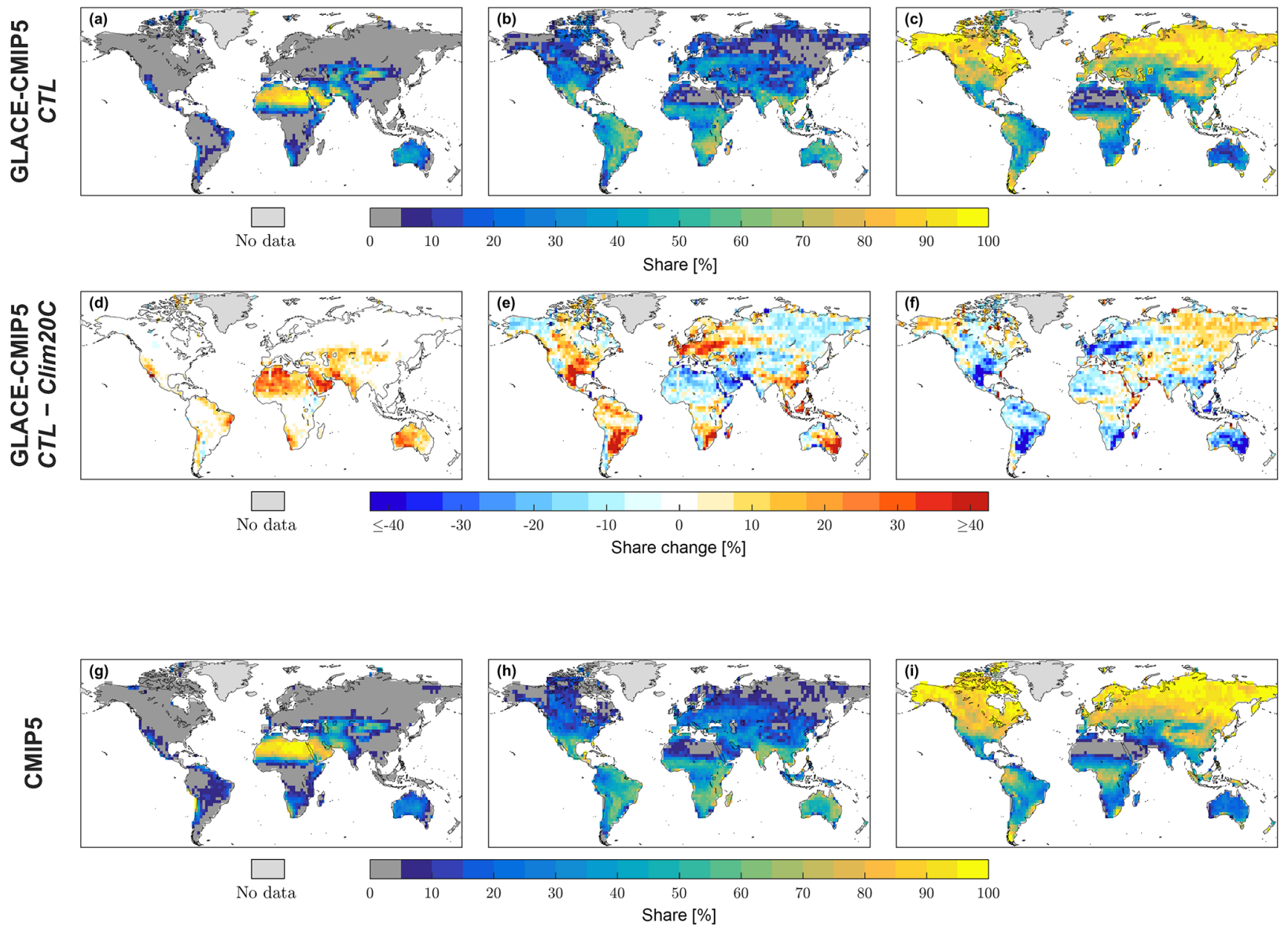

Figure 2. (a-c) The multimodel mean occurrence of the different soil moisture regimes in the GLACE-CMIP5 control run (CTL) for the time period from 2070 to 2099. The percentages indicate how many of the 3-month subsets are located in each regime in the course of the year. (Note that the number of 3-month subsets on a grid point might be less than 12 since we require that all variables involved in calculating EF are positive. This restriction primarily affects grid cells at high latitudes, see Schwingshackl et al., 2017 for more details.) All 3-month subsets that include passages between the transitional regime and another regime are assigned to the occurrence of the transitional regime. (d-f) Differences in soil moisture regime occurrence in GLACE-CMIP5 between the control run (CTL) and the run with prescribed 1971-2000 soil moisture climatology (Clim20C). (g-i) The multimodel mean occurrence of the different soil moisture regimes in the CMIP5 models for the time period from 2070 to 2099.

the GLACE-CMIP5 models and the CMIP5 models as well as the CMIP5 models, and the regime difference between the GLACE-CMIP5 experiments CTL and Clim20C for the time period from 2070 to 2099 are displayed in Fig. 2. The regime classification for the GLACE-CMIP5 control run (Fig. 2ac) reveals that overall the wet regime has the highest share ( $\sim 56 \%$ on area-weighted global average), followed by the transitional $(\sim 29 \%)$ and dry regimes $(\sim 15 \%)$. The wet regime is mostly found at high latitudes and in tropical rainforests, which are climate zones where water is abundant. The transitional regime occurs in many regions at lower latitudes. In particular, several areas in Latin America, Africa, India, Southeast Asia, and Australia are located in the transi- tional regime for more than half of the year. The dry regime shows the highest occurrence in deserts.

Many regions exhibit different regime shares in the two GLACE-CMIP5 experiments CTL and Clim20C (Fig. 2d-f). Desert regions generally reveal an enhanced occurrence of the dry regime in CTL compared to Clim20C, which mostly occurs at the expense of the transitional regime. In other regions the occurrence of the transitional regime increases in the CTL experiment. These hotspot regions include the southeastern US and Mexico, central and eastern Europe, the Paraná catchment in South America, southern Africa, Southeast Asia, and eastern Australia. In the same regions the wet regime shows pronounced decreases. At high latitudes and in tropical rainforests in South America and Africa the regime 
distributions in CTL and Clim20C only differ slightly from one another.

The CMIP5 models show a very similar soil moisture regime distribution as the analyzed GLACE-CMIP5 models in the CTL experiment (Fig. 2g-i). This is further confirmed when the global share of each soil moisture regime for the single climate models is considered (Fig. S3). The four GLACE-CMIP5 models cover a similar spectrum to the 20 CMIP5 models; thus, they seem to be an appropriate CMIP5 model subset for assessing soil moisture effects on climate.

\subsection{Emerging differences in soil moisture experiments}

\subsubsection{GLACE-CMIP5}

An overview of the comparison between different key measures that characterize the effect of soil moisture on EF and TX for the time period from 2070 to 2099 is displayed in Fig. 3 as the multimodel median of the GLACE-CMIP5 models. The measures on the left-hand side of Fig. 3 are calculated directly based on the differences between the GLACECMIP5 experiments CTL and Clim20C (i.e., experimentbased). The measures in the center of Fig. 3 are obtained from the combination of the sensitivities in the different soil moisture regimes of the $\mathrm{EF}(\theta)$ framework (i.e., frameworkbased, see Sect. 3.2 and 3.3 for details regarding the derivation). A description of the single measures can be found in Table 1.

The uppermost row (Fig. 3a-c) displays the sensitivity of EF to soil moisture changes across the two experiments CTL and Clim20C. Both the experiment- and the frameworkbased estimates of $\Delta \mathrm{EF} / \Delta \theta$ highlight similar regions in which soil moisture shifts evoke strong EF changes. In particular, these regions comprise the western and southern US, Mexico, parts of Brazil, the Sahel region, southern Africa, India, Southeast Asia, and Australia. In contrast, the impact of soil moisture on EF is low at high latitudes, in deserts, and in tropical rainforests. The pattern correlation (calculated as Spearman rank correlation $-r_{\mathrm{s}}$ ) between the experiment- and framework-based estimates is 0.85 , indicating good agreement between both estimation methods. The high correlation and the fact that the mean absolute error (MAE; Fig. 3c) is low compared to the actual values confirm that the framework-based estimates are indeed capturing the soil moisture induced EF differences across the soil moisture experiments.

Figure $3 \mathrm{~d}-\mathrm{f}$ show the sensitivity of TX to soil moisture shifts between the two experiments CTL and Clim20C. The negative values reflect the negative coupling between soil moisture and TX. Both the experiment-based and the framework-based estimates of $\Delta \mathrm{TX} / \Delta \theta$ highlight similar regions with strong sensitivity of TX to soil moisture. These regions generally agree with the areas where soil moisture has a strong impact on EF, except for the Sahel region, where the TX sensitivity is weaker, and Europe, where the sensitivity is more pronounced and more widespread. The pattern correlation between the experiment- and the framework-based $\Delta \mathrm{TX} / \Delta \theta$ values is 0.59 indicating general consistency between the two approaches. However, the experiment-based TX sensitivities are generally stronger than the frameworkbased sensitivities (see differences in Fig. 3f). This is particularly true for Canada, the US, northeastern Brazil, southern Africa, eastern Europe, and central Asia.

Figure $3 \mathrm{~g}-\mathrm{i}$ show the average $\mathrm{EF}$ response to soil moisture shifts (the $\delta \mathrm{EF}_{\theta}$ ) between the CTL and Clim20C experiments. There are several distinct hotspot regions, in which EF exhibits a pronounced decrease in CTL compared to Clim20C. The experiment and framework-based estimates generally agree regarding the location and sign of the EF response, which is reflected in the high pattern correlation of 0.69. However, the framework-based estimates exhibit an EF increase in central North America, Uruguay and its surroundings, eastern Africa, and central Asia, where the experimentbased estimates show a decrease. This discrepancy seems related to the soil moisture depth considered: when using surface soil moisture instead of total column soil moisture to calculate the framework-based estimates, the EF increase becomes less pronounced and in some of the affected regions it even changes to a decrease (Fig. S5). This depth dependence might be explained by the predominance of grassland and shrubs in the affected regions. Both of these vegetation types access water in the upper soil layers; thus, EF is more strongly influenced by the evolution of surface soil moisture than total column soil moisture.

The average response of TX to soil moisture shifts between CTL and Clim20C $\left(\delta \mathrm{TX}_{\theta}\right)$ is displayed in Fig. $3 \mathrm{j}-$ 1. The experiment- and the framework-based TX responses show similar values in South America, Africa, India, Southeast Asia, and to an extent in Australia. These are essentially the regions in which soil moisture shifts have an effect on EF (cf. Fig. 3a-c and g-i). However, particularly in the Northern Hemisphere there are some pronounced differences. This is reflected in the lower pattern correlation $\left(r_{\mathrm{s}}=0.42\right)$ compared with the previous measures. The experiment-based values show high TX responses in Europe, central Asia, and to an extent in North America, while the framework-based estimates, in contrast, have lower responses in eastern Europe and central Asia and exhibit a dipole structure in North America.

The impact of shifts in the lowermost (first) percentile of the soil moisture distributions in CTL and Clim20C on $\mathrm{TX}$ (that is $\delta \mathrm{TX}_{\theta_{\mathrm{Q} 1}}$ ) is shown in Fig. $3 \mathrm{~m}-\mathrm{o}$. The soil moisture effect on $\delta \mathrm{TX}_{\theta_{\mathrm{Q} 1}}$ is more pronounced than the effect on $\delta \mathrm{TX}_{\theta}$. This can be explained by the following two reasons: (1) in regions where soil moisture is predominantly in the wet regime, low soil moisture percentiles are more likely to enter the transitional regime than the mean of the distribution (see Fig. 1a); and (2) the lower tails of the soil moisture distribution show a stronger shift between the CTL and Clim20C experiments than the means of the distribution 


\section{Experiment-based} CTL - Clim20C
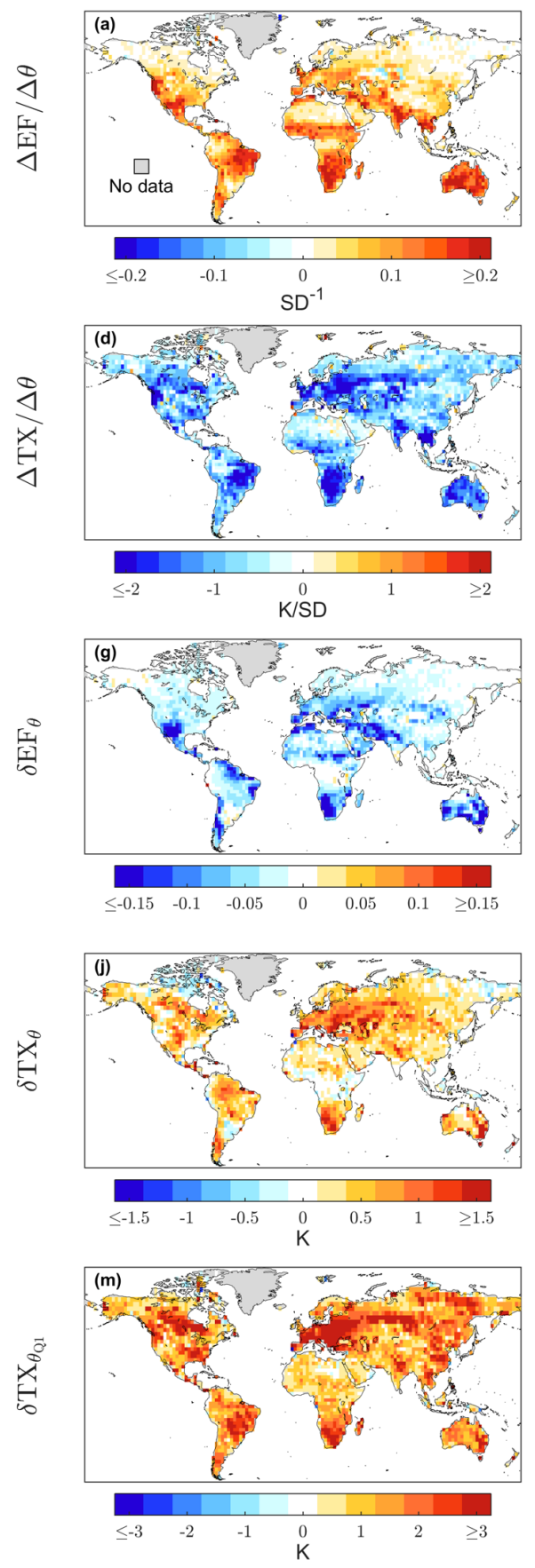

\section{Framework-based} CTL - Clim20C
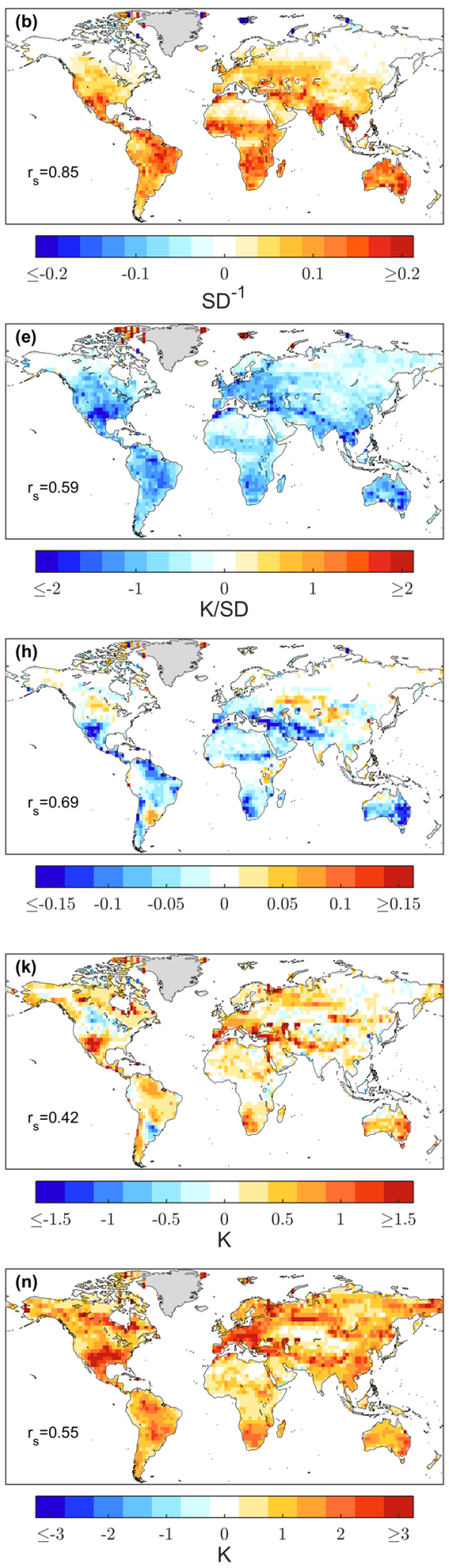

Difference
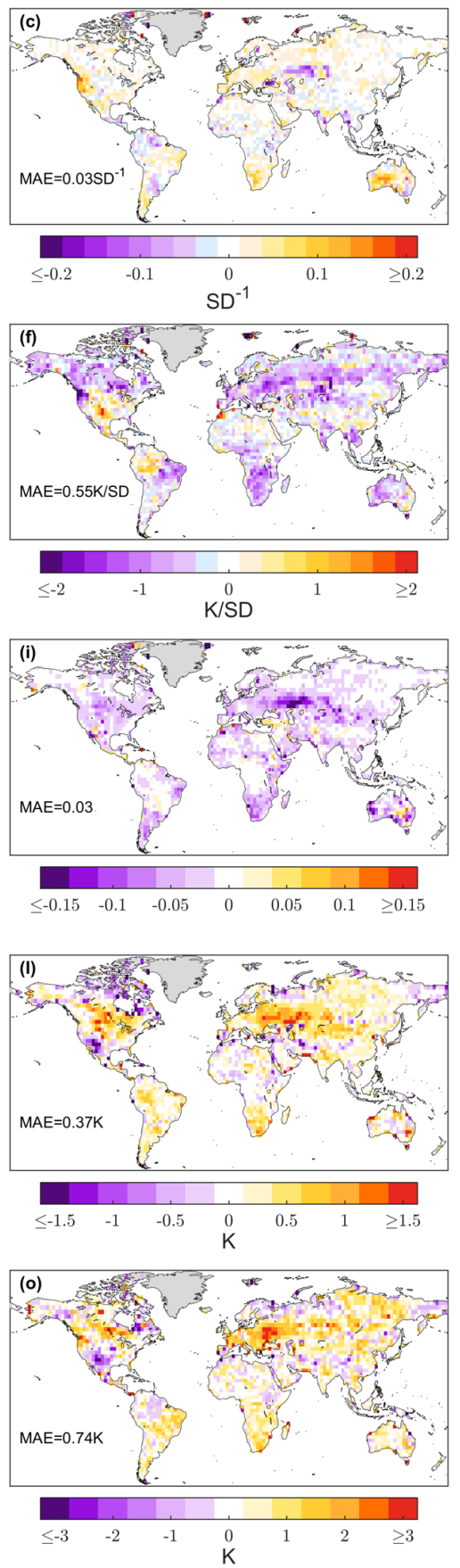

Figure 3. Multimodel median of the GLACE-CMIP5 models for different key measures used to quantify the difference between the soil moisture experiments CTL and Clim20C. Experiment-based estimates (left), framework-based estimates (center), and difference between both estimates (right). The different rows show $(\mathbf{a}-\mathbf{c})$ the sensitivity of the evaporative fraction (EF) to changes in soil moisture $(\theta),(\mathbf{d}-\mathbf{f})$ the sensitivity of daily maximum near-surface air temperature (TX) to changes in $\theta$, (g-i) the absolute EF response to changes in $\theta$, (j-l) the absolute TX response to changes in $\theta$, and $(\mathbf{m}-\mathbf{o})$ the TX change when considering the shift between the lowermost (first) percentile of the soil moisture distributions in CTL and Clim20C. The values are averaged over all 3-month subsets. For each 3-month subset and each climate model, grid cells are masked where the $p$ values of the linear regression coefficient used to calculate the experiment-based estimates (left column) are not significant (the $p$ values were adjusted according to Wilks, 2016). The numbers in the central column indicate the pattern correlation (Spearman rank coefficient $-r_{\mathrm{S}}$ ) between the experiment- and framework-based estimates. The numbers in the right column indicate the mean absolute error (MAE) between both estimation methods. 
Table 1. Overview of the measures used in this study to quantify the effect of soil moisture $(\theta)$ prescriptions on the evaporative fraction (EF) and daily maximum near-surface air temperature (TX).

\begin{tabular}{ll}
\hline Measure & Description \\
\hline$\Delta \mathrm{EF} / \Delta \theta$ & Sensitivity of EF to soil moisture shifts between the experiments CTL and Clim20C (or CTL and ClimCTL) \\
$\Delta \mathrm{TX} / \Delta \theta$ & Sensitivity of TX to soil moisture shifts between the experiments CTL and Clim20C (or CTL and ClimCTL) \\
$\delta \mathrm{EF}_{\theta}$ & Absolute response of EF to the mean soil moisture shift between the two experiments considered \\
$\delta \mathrm{TX}_{\theta}$ & Absolute response of TX to the mean soil moisture shift between the two experiments considered \\
$\delta \mathrm{TX}_{\theta \mathrm{Q} 1}$ & Absolute response of TX caused by the shift in the lowermost (first) percentile \\
$\Delta \mathrm{TX}_{x}$ & of the soil moisture distributions in the two experiments considered \\
\hline
\end{tabular}

(this is essentially caused by the construction of Clim20C which does not allow for any soil moisture values outside of the 1971-2000 climatology, see Fig. 1b). TX is impacted by changes of low soil moisture percentiles primarily in Europe, Canada, Brazil, southern Africa, western Australia, and some parts of central Asia, with values that reach up to more than $3 \mathrm{~K}$. Both estimation methods agree regarding the overall patterns $\left(r_{\mathrm{s}}=0.55\right)$. However, the experiment-based estimates are higher in eastern Europe and Brazil, while the framework-based estimates reveal higher values in the southern US and northern Mexico.

Overall, the experiment- and framework-based estimates of the various measures agree rather well, in particular for $\Delta \mathrm{EF} / \Delta \theta$ and $\delta \mathrm{EF}_{\theta}$. In addition, in the regions where soil moisture affects EF, both the experiment- and frameworkbased estimates of $\delta \mathrm{TX}_{\theta}$ and $\delta \mathrm{TX}_{\theta_{\mathrm{Q} 1}}$ reveal similar patterns and are of comparable strength.

\subsubsection{CMIP5}

Figure 4 shows the same measures as the previous section but as the multimodel median obtained from the framework-based estimates of the CMIP5 models. Generally, the patterns are very similar to the results for the GLACECMIP5 models (cf. Fig. 3), but the patterns are more pronounced and less noisy overall - likely a consequence of the larger CMIP5 model ensemble (20 models) compared with GLACE-CMIP5 (4 models). Both model ensembles highlight similar regions where the sensitivity of EF to soil moisture is high (Figs. $4 \mathrm{a}$ and $3 \mathrm{~b}$ ). In the CMIP5 models the sensitivities are somewhat stronger in India, Southeast Asia, and the Mediterranean region. The sensitivities of TX (Figs. 4b and 3e) are stronger in CMIP5 in the Mediterranean region, central Europe, South Africa, India, and Southeast Asia, while the GLACE-CMIP5 models show more pronounced TX sensitivities in the southern US/Mexico. The patterns of the EF response to soil moisture shifts are similar in CMIP5 and GLACE-CMIP5 (Figs. 4c and 3h), but the CMIP5 models exhibit stronger $\mathrm{EF}$ responses around the Mediterranean Sea, in eastern Africa, and in central Asia. The TX responses (Figs. $4 \mathrm{~d}$ and 3k) are higher in the CMIP5 in the southern US/Mexico, the Mediterranean, and South Africa. The TX decreases provoked by soil moisture shifts (i.e., negative TX values in Figs. 4d and 3k) occur in Patagonia, eastern Africa, India, and Southeast Asia, but are less pronounced in CMIP5 compared to GLACE-CMIP5. The regions in which changes in the first soil moisture percentile have a strong effect on TX are more confined when using the CMIP5 models (Figs. 4e and $3 n$ ). They mainly comprise the southern US/Mexico, the east side of the Andes in South America, central and eastern Europe, the Mediterranean, southern Africa, and China.

Overall, the patterns of the GLACE-CMIP5 and the CMIP5 models agree very well. However, the results should be used and interpreted cautiously in regions where the experiment- and framework-based estimates for GLACECMIP5 reveal differences (Fig. 3, right column; see also Sect. 5).

\subsection{Soil moisture effect on $\mathrm{TX}_{X}$}

The soil moisture effect on $\mathrm{TX}_{x}$ calculated from the framework-based estimates is displayed in Fig. 5 as a multimodel median for the GLACE-CMIP5 and the CMIP5 models for the model-specific time when $T_{\text {glob }}$ increases by 1.5 , 2.0 , and $3.0 \mathrm{~K}$ with respect to preindustrial levels. Overall, the GLACE-CMIP5 models show a stronger (but more noisy) effect on $\mathrm{TX}_{x}$ than the CMIP5 models. The soil moisture contributions to $\mathrm{TX}_{x}$ become larger for higher $\Delta T_{\mathrm{glob}}$. Both model ensembles show strong soil moisture impacts on $\mathrm{TX}_{x}$ in the southern US/Mexico, the Gran Chaco region in South America, southern Africa, China, and western Australia. For Europe, the CMIP5 models predict higher soil moisture effects than the GLACE-CMIP5 models. The GLACE-CMIP5 models reveal high values in Canada, Alaska, and Asia, where the CMIP5 models only show a slight increase. These high values in GLACE-CMIP5 are caused by both the ACCESS and the GFDL models, which exhibit strong soil moisture shifts between the different experiments in the abovementioned regions (not shown). The CMIP5 models predict a strong increase of the soil moisture effect on $\mathrm{TX}_{x}$ at higher $\Delta T_{\text {glob }}$ in the southern US/Mexico and Europe (and also to some extent in southern Africa and China), while elsewhere the impact on $\mathrm{TX}_{x}$ remains approximately constant. 

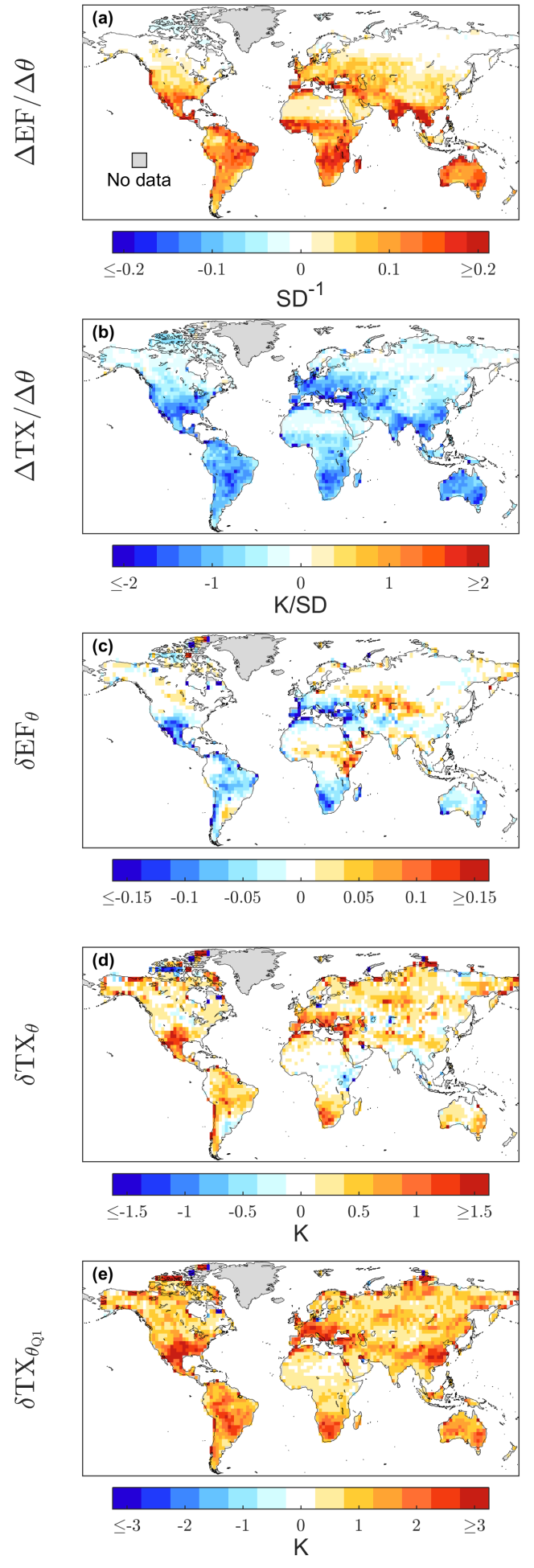

Figure 4. As in Fig. 3 (central column); the framework-based estimates, but for the CMIP5 multimodel median.

Figure 6 shows the $\Delta \mathrm{TX}_{x}$ evolution as function of $\Delta T_{\text {glob }}$ in six different SREX regions (see Sect. 3.1.3), in which soil moisture effects are expected to be important (e.g., Mi- ralles et al., 2012; Schwingshackl et al., 2017; Vogel et al., 2017). The shaded areas indicate the $\Delta \mathrm{TX}_{x}$ ranges directly obtained from the GLACE-CMIP5 experiments CTL and Clim20C. The red box and whisker plots represent 20-year average $\Delta \mathrm{TX}_{x}$ distributions in CTL around the indicated $T_{\text {glob }}$ levels. To account for the effect that soil moisture shifts between CTL and Clim20C have on $\mathrm{TX}_{x}$, the frameworkbased soil moisture effect on $\mathrm{TX}_{x}$ is subtracted from the 20-year average $\Delta \mathrm{TX}_{x}$ (see Sect. 3.3.2). The resulting soil moisture effect-corrected $\Delta \mathrm{TX}_{x}$ is represented by the blue box and whisker plots. For CTL the experiment-based estimates reveal a faster increase for $\Delta \mathrm{TX}_{x}$ than for $\Delta T_{\mathrm{glob}}$ - a characteristic that was also shown by Seneviratne et al. (2016) and Vogel et al. (2017). However, when soil moisture is prescribed according to Clim $20 \mathrm{C}$ (blue range), the excess increase is almost completely offset (cf. Vogel et al., 2017). The framework-based $\Delta \mathrm{TX}_{x}$ estimates also show a slower increase of $\mathrm{TX}_{x}$ for Clim20C (blue box and whisker plots) compared to CTL (red box and whisker plots). In central North America, the Amazon, the Mediterranean, southern Africa, and northern Australia the framework- and the experiment-based $\Delta \mathrm{TX}_{x}$ estimates are in good agreement. However, the framework-based estimates generally exhibit a smaller difference between CTL and Clim20C than the experiment-based estimates. In contrast to the good agreement in these regions, the soil moisture effect calculated from the framework-based estimates for central Europe yields much weaker impacts than the experiment-based effect on $\Delta \mathrm{TX}_{x}$.

An overview of $\Delta \mathrm{TX}_{x}$ in CTL and Clim20C using the framework-based estimates for both GLACE-CMIP5 and CMIP5 is shown in Fig. 7. Generally, both model sets give similar results. Especially in the Amazon and central Europe, the CMIP5 and the GLACE-CMIP5 estimations agree well. However, they also reveal differences in some regions. The CMIP5 models exhibit a narrower spread than GLACECMIP5 in central North America and the Mediterranean. In southern Africa and northern Australia the $\Delta \mathrm{TX}_{x}$ spread of CMIP5 is larger than that from GLACE-CMIP5. In central North America and southern Africa the CMIP5 models show stronger soil moisture effects on $\mathrm{TX}_{x}$ than the GLACECMIP5 models, while in northern Australia the effects are lower.

\section{Discussion}

The theoretical framework-based approach constitutes a simple and powerful tool to evaluate how soil moisture shifts across the different GLACE-CMIP5 experiments affect EF and TX. Because the soil moisture evolution is the only imposed difference between the GLACE-CMIP5 experiments CTL, Clim20C, and ClimCTL, the resulting climate effects can be directly attributed to differences in soil moisture. The possibility to establish this causal link is a main advantage of 


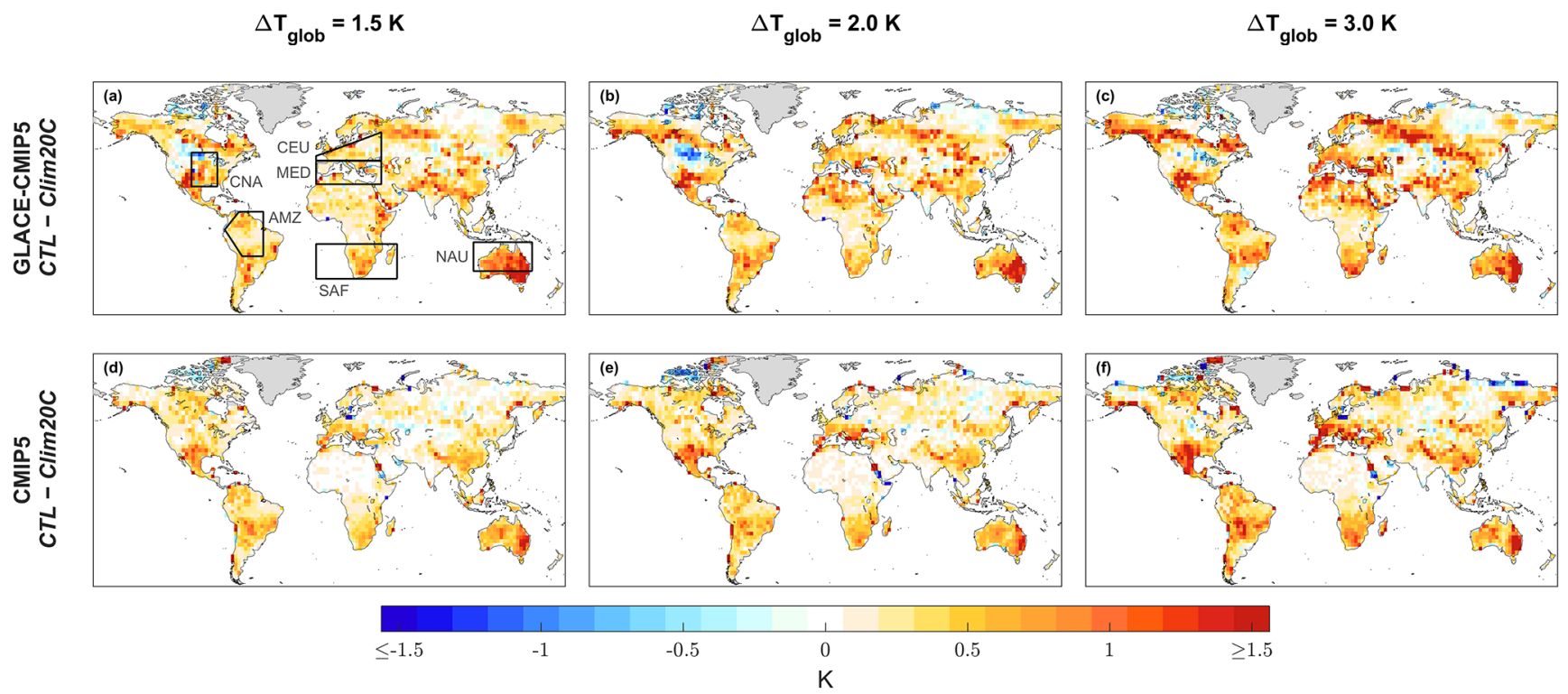

Figure 5. The multimodel median of the soil moisture contribution to the yearly maximum value of daily maximum temperature (TX $\mathrm{T}_{x}$ ) calculated from the soil moisture difference between CTL and Clim20C in the GLACE-CMIP5 (a-c) and CMIP5 models (d-f) using the framework-based estimates. The different columns show the soil moisture contribution to $\mathrm{TX}_{x}$ when global mean temperature increase $\Delta T_{\text {glob }}$ reaches $(\mathbf{a}, \mathbf{d}) 1.5 \mathrm{~K},(\mathbf{b}, \mathbf{e}) 2.0 \mathrm{~K}$, and $(\mathbf{c}, \mathbf{f}) 3.0 \mathrm{~K}$ above preindustrial temperature levels. The frames in (a) highlight the SREX regions, for which the temporal evolution of $\mathrm{TX}_{x}$ is shown in Figs. 6 and 7. The definitions of the region abbreviations can also be found in Figs. 6 and 7.

the idealized GLACE-CMIP5 experiments. The good agreement between the experiment- and framework-based estimates of the soil moisture effects on EF is also an indirect validation of the applied $\operatorname{EF}(\theta)$ framework and gives confidence that it is able to represent the cause-effect relations of soil moisture-climate coupling.

To obtain the framework-based estimates no other model data apart from the CMIP5 standard output is required. Thus, the methodology can be used to estimate soil moistureclimate coupling without the need to perform additional model simulations. Especially for investigating the soil moisture control on EF, the framework-based estimates seem to give reliable results, as can be seen from the comparison with the experiment-based estimates in Fig. 3a-c. Additionally, in the regions where the sensitivity of EF to soil moisture is particularly pronounced, both the experiment- and the framework-based estimates of $\delta \mathrm{TX}_{\theta}$ and $\delta \mathrm{TX}_{\theta_{\mathrm{Q} 1}}$ agree well. This is a strong indication that the different soil moisture prescriptions in the GLACE-CMIP5 experiments affect TX directly through the soil moisture control on the partitioning of net radiation into latent and sensible heat fluxes in these regions.

Nevertheless, there are some regions where the experiment- and the framework-based estimates of soil moisture-climate coupling disagree. There are several possible explanations for these differences. The first is based on the regime classification, which is central for calculating the framework-based estimates. If soil moisture only enters a certain regime rarely, the regime classification might not be sensitive enough to distinguish this regime from the predominant regime and the rare regime could thus be missed. As a result, $\partial \mathrm{EF} / \partial \theta$ might be over- or under-estimated, yielding biased estimates for the average effect on EF (and similarly on TX). Secondly, evapotranspiration and thus EF can be influenced by soil moisture in different depths. While evaporation from bare soil and transpiration from short vegetation are mostly dependent on soil moisture conditions in the surface soil layer, tall vegetation can additionally access water in deeper layers. As the projected trends of surface and total column soil moisture diverge in several regions of the globe (Berg et al., 2017), the results presented in this study to some extent are dependent on the chosen soil moisture depth This is reflected in the sign change of the $\mathrm{EF}$ response in certain regions when replacing total column soil moisture by surface soil moisture (Figs. 3h and S5c). In addition, prescribing soil moisture in the GLACE-CMIP5 experiments might not only influence the heat fluxes, but may also lead to secondary effects caused by other soil moisture feedbacks. Berg et al. (2014) showed that for the soil moisture experiments conducted with the GFDL model not only latent heat flux, but also leaf area index, cloud cover, and potential evaporation all differ between the single experiments. Moreover, soil moisture can also impact atmospheric temperatures by changing the thermal properties (e.g., the heat capacity and thermal resistance) of the soil (Cheruy et al., 2017). As long as these effects 

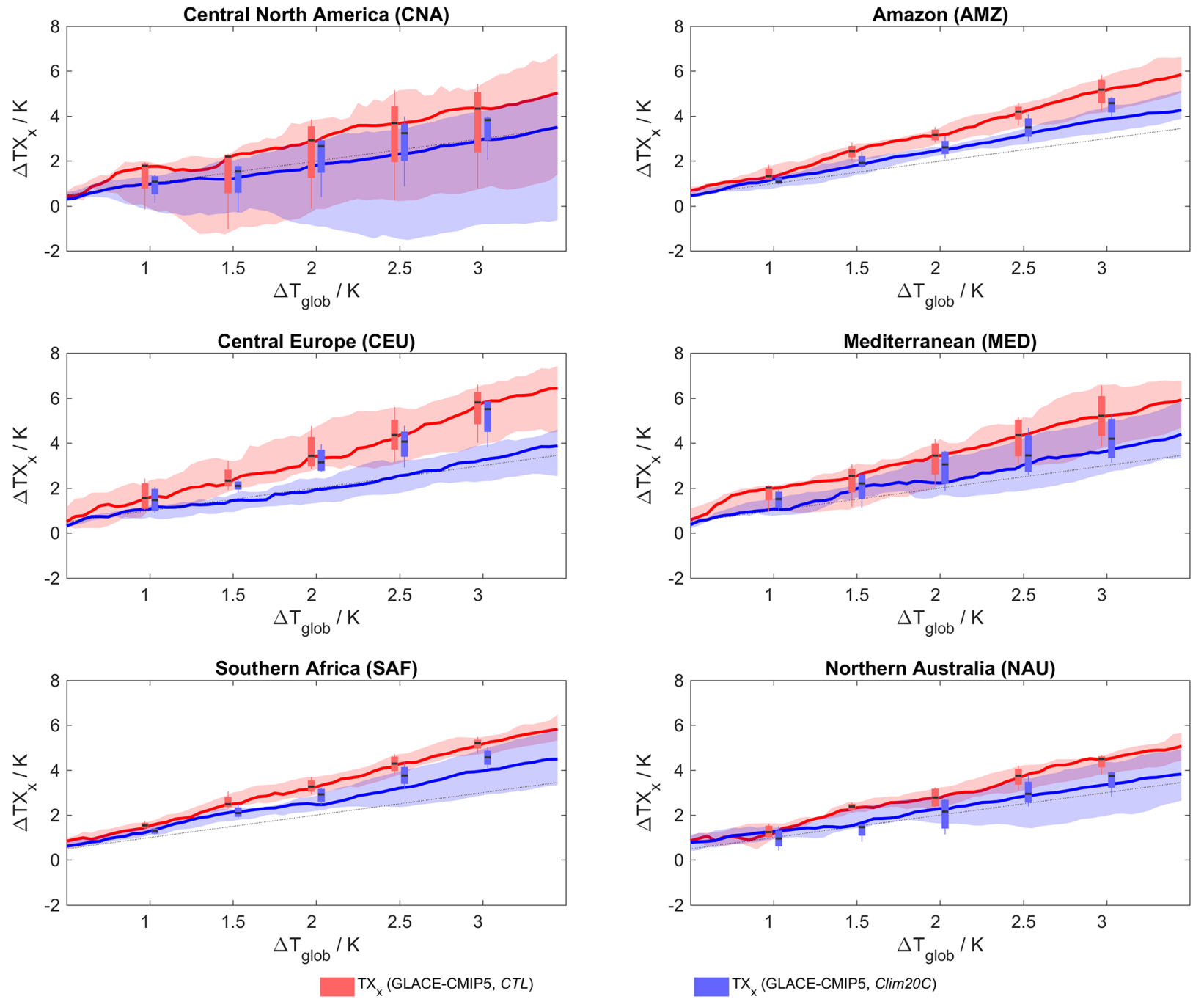

$\operatorname{TX}_{x}$ (GLACE-CMIP5, Clim20C)

Figure 6. Changes of the yearly maximum value of daily maximum temperature $\left(\Delta \mathrm{TX}_{x}\right)$ scaled with the global mean temperature increase $\left(\Delta T_{\text {glob}}\right)$ in the GLACE-CMIP5 experiments CTL (in red) and Clim20C (in blue) for six different SREX regions (the extent of each region is highlighted in Fig. 5a). $\Delta \mathrm{TX}_{x}$ and $\Delta T_{\text {glob }}$ both refer to the base period from 1951 to 1970 (corrected with $0.22 \mathrm{~K}$ for the $T_{\text {glob }}$ increase between 1871-1890 and 1951-1970). The shaded areas represent directly estimated $\triangle \mathrm{TX}_{x}$ from the CTL and Clim20C GLACE-CMIP5 experiments. The range of the shaded areas indicates the minimum and maximum values of all models, the line indicates the median. The red box and whisker plots are 20-year averages of $\Delta \mathrm{TX}_{x}$ in CTL (centered on the year when $\Delta T_{\text {glob }}$ reaches 1.0, 1.5, 2.0, 2.5, and 3.0 K). The blue box and whisker plots show the 20-year average $\Delta \mathrm{TX}_{x}$ minus the framework-based soil moisture effect on $\Delta \mathrm{TX}_{x}$ (i.e., accounting for soil moisture effects on $\mathrm{TX}_{x}$ ). The line in the box represents the median, the box the interquartile range, and the whiskers are the minimum and maximum values. The dashed curve indicates the identity line.

feed back on evapotranspiration, they can, in principal, be captured by the $\operatorname{EF}(\theta)$ framework. However, the complex coupling between the land surface and the atmosphere can generate additional nonlinearities beyond the presence of a critical soil moisture threshold for evapotranspiration (Fig. 1a) and influence the atmosphere by processes that are not taken into account by the $\operatorname{EF}(\theta)$ framework.

Another important and maybe even more relevant aspect are non-local soil moisture effects on the atmosphere (e.g., Seneviratne et al., 2013; Koster et al., 2014). For instance, thermal advection could be responsible for transporting temperature signals to regions downwind of areas that experience strong local soil moisture-climate coupling (Seneviratne et al., 2013). Differences in the patterns between the framework-based estimates (which measure the local soil moisture-climate coupling strength) and the experimentbased estimates (which include both local and non-local effects) might thus give an indication about remote effects caused by soil moisture shifts. For example, the stronger TX signal in the experiment-based estimates in central North 

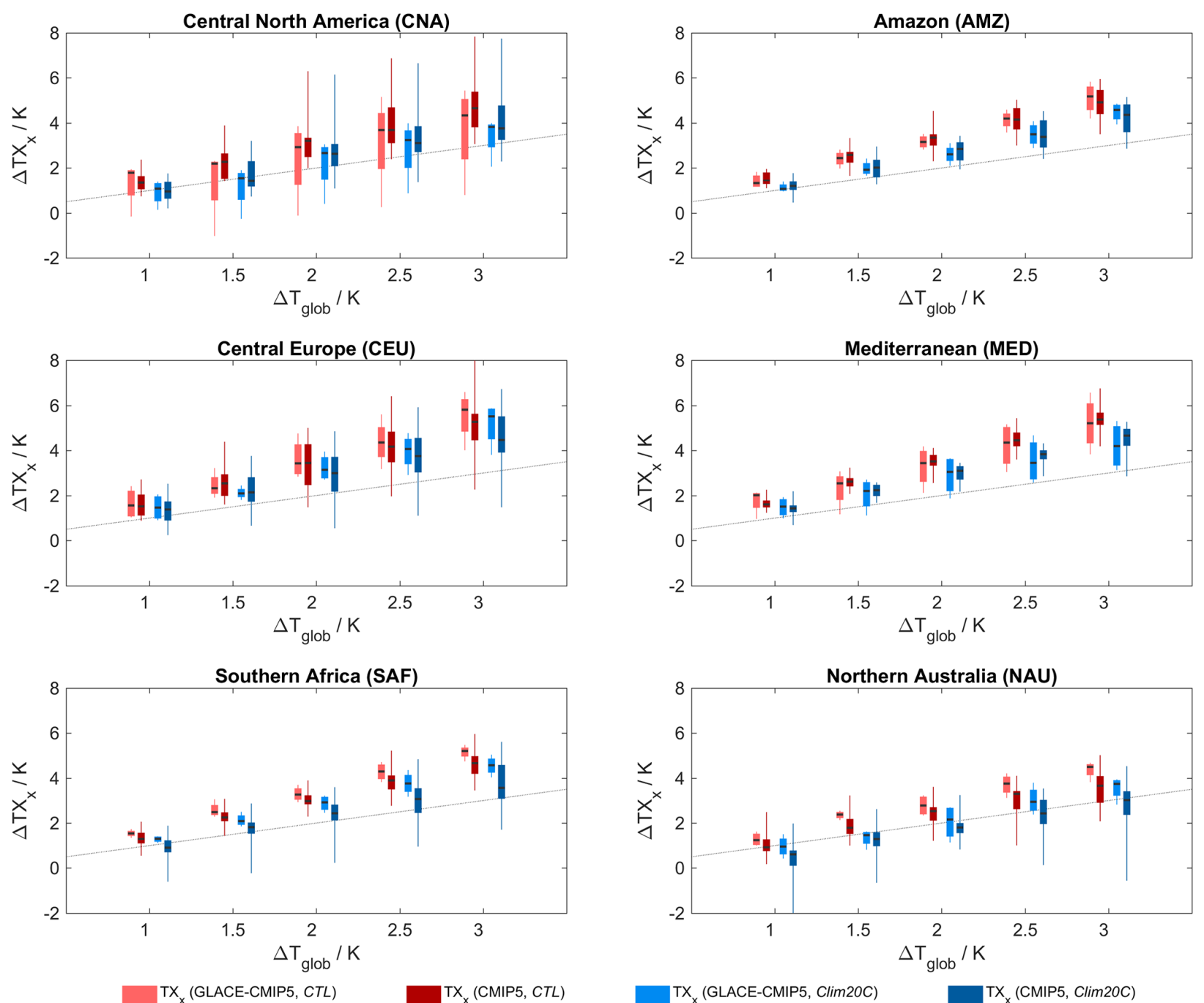

Figure 7. As in Fig. 6 but including CMIP5 models and without directly estimated $\triangle \mathrm{TX}_{x}$ from the GLACE-CMIP5 experiments. The different box and whisker plot groups (always containing four box and whisker plots) show the effects when $\Delta T_{\text {glob }}$ reaches $1.0,1.5,2.0$, 2.5 , and $3.0 \mathrm{~K}$.

America and eastern Europe/central Asia (Fig. 3j-1) indicate that westerlies transport the soil moisture signal from the US West Coast and Europe towards the east.

In several regions, the effect of soil moisture shifts on EF is connected to regime shifts between the different soil moisture experiments (see Figs. 2d-f and 3). However, the effect on EF is not only limited to the regions that exhibit regime shifts between the soil moisture experiments; soil moisture changes within one soil moisture regime can also have an impact on climate. Moreover, the strong dependency of EF on soil moisture is not necessarily translated into effects on TX; a good example of this is the Sahel region, where soil moisture impacts EF but effects on TX are rather low. An area with particularly high impacts of soil moisture on TX is Europe. This region is of special interest because the experiment-based TX response clearly ex- ceeds the framework-based response (Fig. 3j-0), although Europe shows different soil moisture regime shares in the CTL and Clim20C experiments (Fig. 2d-f); thus, one would expect that the framework-based estimates show a strong TX response. As discussed above, the discrepancy between the experiment- and framework-based estimates points to additional feedbacks (such as circulation changes or soil moisture-precipitation feedbacks) that are not captured by the framework-based estimation, but might be important for soil moisture-temperature coupling in Europe.

The soil moisture effect on TX is generally expected to be strongest for extreme conditions (Hirschi et al., 2011; Fischer and Schär, 2009; Seneviratne et al., 2016; Vogel et al., 2017). This is confirmed by our results which show a larger effect from shifts of the first soil moisture percentile than for mean soil moisture shifts (Figs. $3 \mathrm{j}-\mathrm{O}$ and $4 \mathrm{~d}-\mathrm{e}$ ) as well as 
pronounced impacts on $\mathrm{TX}_{x}$ (Fig. 5). However, these results have to be interpreted with some caution, since the Clim20C and ClimCTL soil moisture experiments are limited to prescribed soil moisture climatologies and consequently have different soil moisture distributions than CTL; this difference primarily affects the tails of the soil moisture distributions. Moreover, incorrect soil moisture regime classifications which result in incorrect sensitivity estimations - affect the results more strongly during very low soil moisture conditions than during average soil moisture conditions. Since soil moisture mostly impacts extremes during low soil moisture conditions, the estimated soil moisture contributions to $\mathrm{TX}_{x}$ are especially affected by possible incorrect sensitivity estimations.

Soil moisture effects on $\mathrm{TX}_{x}$ are particularly strong in the southern US/Mexico, Europe, and western Australia. Vogel et al. (2017), whose results we attempt to confirm here by calculating soil moisture contributions to $\mathrm{TX}_{x}$ from the framework-based estimates, showed that considering soil moisture effects is important for explaining the large $\mathrm{TX}_{x}$ increases in the abovementioned regions. The results of the present study are in agreement with the conclusions of Vogel et al. (2017). Note that the two studies do not use the exact same GLACE-CMIP5 model (sub-)ensemble, and the results consequently reveal some marginal differences.

While the framework-based soil moisture effects on $\mathrm{TX}_{x}$ yield similar results to those directly obtained from the GLACE-CMIP5 experiments in many regions (Fig. 6), there are large differences especially for central Europe, where the framework-based estimates predict a smaller soil moisture effect than those directly estimated from the GLACE-CMIP5 experiments. Again, this fact hints at secondary feedbacks triggered by soil moisture shifts between the GLACE-CMIP5 experiments. These secondary effects on $\mathrm{TX}_{x}$ seem to be largest in Europe, while in the other regions investigated the direct soil moisture effect explains most of the observed differences.

All of the framework-based estimates for GLACE-CMIP5 can be either obtained with soil moisture climatologies calculated according to the GLACE-CMIP5 protocol or with soil moisture directly taken from the respective GLACE-CMIP5 soil moisture experiments. Here we use the former approach to be consistent with the calculation for the CMIP5 models. In general, the results are similar, independent of the soil moisture choice for GLACE-CMIP5. Only in the Amazon and in southern Africa is the $\Delta \mathrm{TX}_{x}$ spread enhanced when using soil moisture directly from the GLACE-CMIP5 runs (not shown). The reason for this might be the unintended soil moisture shift in ACCESS in Clim20C (see Sect. 3.1.1).

When considering the differences between the CTL experiment and the transient soil moisture climatology ClimCTL (Figs. S6-S10), the soil moisture effect on TX and $\mathrm{TX}_{x}$ is not as strong as the difference between CTL and Clim20C. There are some impacts on $\mathrm{TX}_{x}$ in middle-to-high latitudes in the Northern Hemisphere (particularly in the US, Europe, and China), but they are considerably smaller than the effects in Clim20C. This confirms the finding of Vogel et al. (2017) that soil moisture impacts on extreme temperatures are due to long-term soil moisture trends rather than to changes in soil moisture variability alone.

\section{Conclusions}

In this study we analyze the effect that different soil moisture prescriptions in the single GLACE-CMIP5 experiments have on the evaporative fraction (EF) and daily maximum near-surface air temperature (TX). The analyses are based on an idealized framework (Fig. 1a) that describes the relation between soil moisture $(\theta)$ and EF by considering different soil moisture regimes (Koster et al., 2009; Seneviratne et al., 2010). This framework was found to be well suited to quantify the impact of soil moisture on heat fluxes and daily maximum near-surface air temperature (Schwingshackl et al., 2017), highlighting its applicability for studying soil moisture-climate coupling.

Using a theoretical approach based on the different sensitivities of EF and TX to soil moisture in the single soil moisture regimes of the $\operatorname{EF}(\theta)$ framework, soil moisture-climate coupling in the GLACE-CMIP5 experiments can be quantified and explained. In particular, the effect of soil moisture shifts on EF and TX across GLACE-CMIP5 experiments can be reproduced (Fig. 3). Especially for the soil moisture impact on EF, the framework-based estimates agree very well with estimations of the coupling strength directly calculated from the GLACE-CMIP5 soil moisture experiments. Furthermore, in regions where soil moisture exerts control on latent heat fluxes, the impact of soil moisture on TX is reliably reproduced by the framework-based estimates. The good agreement between the experiment- and frameworkbased estimates of the soil moisture effects gives confidence that the approach used, which is based on the $\mathrm{EF}(\theta)$ framework, is able to represent cause-effect relations of soil moisture-climate coupling. In addition, the differences between the sensitivity- and the experiment-based estimates give an indication of non-local climate effects that are caused by soil moisture shifts between the different GLACE-CMIP5 experiments. Since the framework-based estimates only require input data from the control run (i.e., no additional simulations), the method can be directly applied to CMIP5 models. The patterns of strong soil moisture-climate coupling obtained for CMIP5 are in accordance with those estimated from GLACE-CMIP5 (Fig. 4). Moreover, the larger CMIP5 model ensemble increases the reliability and robustness of the calculated soil moisture effects on EF and TX. Thus, the framework-based approach constitutes a powerful method for assessing soil moisture-climate coupling in both GLACE-CMIP5 and CMIP5.

Eventually, the soil moisture contributions to the yearly maximum value of the daily maximum temperature $\mathrm{TX}_{x}$ are 
quantified using the framework-based estimates (Figs. 5-7). The results highlight the important impact of soil moisture on $\mathrm{TX}_{x}$ in various regions on Earth. In most of the investigated regions the sensitivity- and experiment-based estimations of the soil moisture contributions to $\mathrm{TX}_{x}$ agree. However, in central Europe the soil moisture contribution to $\mathrm{TX}_{x}$ calculated from the framework-based estimates is lower than that directly obtained from the different GLACE-CMIP5 experiments. This points to secondary effects of soil moisture prescriptions on circulation, precipitation, and cloud cover (Seneviratne et al., 2013; Berg et al., 2015) that seem to be important, for example, in central Europe.

The theoretical approach presented, which is based on the use of the $\operatorname{EF}(\theta)$ framework to quantify soil moisture-climate coupling in GLACE-CMIP5, constitutes a well suited tool that can be applied without the need for specific soil moisture prescription experiments. In addition, it can easily be applied to CMIP5 models to emulate GLACE-style soil moisture prescription in regions where local soil moistureatmosphere feedbacks dominate. Thus, it provides an option to avoid costly climate model experiments and can be applied to various climate model environments to quantify the soil moisture-climate coupling strength.

Data availability. GLACE-CMIP5 data are hosted at ETH Zürich and are available upon request (see http://www.iac.ethz.ch/group/ land-climate-dynamics/research/glace-cmip.html). CMIP5 data can be downloaded at https://esgf-node.llnl.gov/search/cmip5.

Supplement. The supplement related to this article is available online at: https://doi.org/10.5194/esd-9-1217-2018-supplement.

Author contributions. CS conducted the analysis and wrote the paper. MH gave significant input during the method implementation and provided feedback on the paper. SIS contributed the initial idea for the study, gave input on the methods used, and provided funding.

Competing interests. The authors declare that they have no conflict of interest.

Acknowledgements. We thank Kirsten Findell, Wilhelm May, and Stefan Hagemann for constructive feedback on the paper. This study was supported by the European Research Council (ERC) "DROUGHT-HEAT" project funded through the European Community's Seventh Framework Programme (grant agreement FP7-IDEAS-ERC-617518). We acknowledge the World Climate Research Programme's Working Group on Coupled Modelling, which is responsible for CMIP, and we thank the climate modeling groups (listed in Table S1) for producing and making available their model output. For CMIP the U.S. Department of Energy's Program for Climate Model Diagnosis and Intercomparison provides coordinating support and led the development of software infrastructure in partnership with the Global Organization for Earth System Science Portals. We thank the GEWEX (World Climate Research Programme, WCRP) and iLEAPS (Integrated Geosphere-Biosphere Programme, IGBP) projects for the coordination and realization of the GLACE-CMIP5 experiment. We also thank Alexis Berg, Frederique Cheruy, Stefan Hagemann, David Lawrence, Ruth Lorenz, Arndt Meier, Anna Ukkola, and Bart van den Hurk for providing the GLACE-CMIP5 simulations.

Edited by: Zhenghui Xie

Reviewed by: two anonymous referees

\section{References}

Berg, A., Lintner, B. R., Findell, K. L., Malyshev, S., Loikith, P. C., and Gentine, P.: Impact of Soil Moisture-Atmosphere Interactions on Surface Temperature Distribution, J. Climate, 27, 79767993, https://doi.org/10.1175/JCLI-D-13-00591.1, 2014.

Berg, A., Lintner, B. R., Findell, K., Seneviratne, S. I., van den Hurk, B., Ducharne, A., Chéruy, F., Hagemann, S., Lawrence, D. M., Malyshev, S., Meier, A., and Gentine, P: Interannual coupling between summertime surface temperature and precipitation over land: Processes and implications for climate change, J. Climate, 28, 1308-1328, https://doi.org/10.1175/JCLI-D-14$00324.1,2015$.

Berg, A., Findell, K., Lintner, B., Giannini, A., Seneviratne, S. I., van Den Hurk, B., Lorenz, R., Pitman, A., Hagemann, S., Meier, A., et al.: Land-atmosphere feedbacks amplify aridity increase over land under global warming, Nat. Clim. Change, 6, 869-874, https://doi.org/10.1038/NCLIMATE3029, 2016.

Berg, A., Sheffield, J., and Milly, P. C.: Divergent surface and total soil moisture projections under global warming, Geophys. Res. Lett., 44, 236-244, https://doi.org/10.1002/2016GL071921, 2017.

Casagrande, E., Mueller, B., Miralles, D. G., Entekhabi, D., and Molini, A.: Wavelet correlations to reveal multiscale coupling in geophysical systems, J. Geophys. Res.-Atmos., 120, 7555-7572, https://doi.org/10.1002/2015JD023265, 2015.

Cheruy, F., Dufresne, J. L., Aït Mesbah, S., Grandpeix, J. Y., and Wang, F.: Role of Soil Thermal Inertia in Surface Temperature and Soil Moisture-Temperature Feedback, J. Adv. Model. Earth Sy., 9, 2906-2919, https://doi.org/10.1002/2017MS001036, 2017.

de Jeu, R. A. M., Wagner, W., Holmes, T. R. H., Dolman, A. J., van de Giesen, N. C., and Friesen, J.: Global Soil Moisture Patterns Observed by Space Borne Microwave Radiometers and Scatterometers, Surv. Geophys., 29, 399-420, https://doi.org/10.1007/s10712-008-9044-0, 2008.

Dirmeyer, P. A.: The terrestrial segment of soil moistureclimate coupling, Geophys. Res. Lett., 38, L16702, https://doi.org/10.1029/2011GL048268, 2011.

Dorigo, W. A., Wagner, W., Hohensinn, R., Hahn, S., Paulik, C., Xaver, A., Gruber, A., Drusch, M., Mecklenburg, S., van Oevelen, P., Robock, A., and Jackson, T.: The International Soil Moisture Network: a data hosting facility for global in situ soil moisture measurements, Hydrol. Earth Syst. Sci., 15, 1675-1698, https://doi.org/10.5194/hess-15-1675-2011, 2011.

Dorigo, W., Wagner, W., Albergel, C., Albrecht, F., Balsamo, G., Brocca, L., Chung, D., Ertl, M., Forkel, M., Gruber, A., Haas, E., 
Hamer, P. D., Hirschi, M., Ikonen, J., de Jeu, R., Kidd, R., Lahoz, W., Liu, Y. Y., Miralles, D., Mistelbauer, T., Nicolai-Shaw, N., Parinussa, R., Pratola, C., Reimer, C., van der Schalie, R., Seneviratne, S. I., Smolander, T., and Lecomte, P.:: ESA CCI Soil Moisture for improved Earth system understanding: state-of-the art and future directions, Remote Sens. Environ., 203, 185-215, https://doi.org/10.1016/j.rse.2017.07.001, 2017.

Fischer, E. M. and Schär, C.: Future changes in daily summer temperature variability: driving processes and role for temperature extremes, Clim. Dynam., 33, 917-935, https://doi.org/10.1007/s00382-008-0473-8, 2009.

Global Land-Atmosphere Coupling Experiment-Coupled Model Intercomparison Project phase 5 (GLACE-CMIP5), available at: http://www.iac.ethz.ch/group/land-climate-dynamics/ research/glace-cmip.html, last access: 10 October 2018.

Hauser, M., Orth, R., and Seneviratne, S. I.: Role of soil moisture vs. recent climate change for the 2010 heat wave in western Russia, Geophys. Res. Lett., 43, 2819-2826, https://doi.org/10.1002/2016GL068036, 2016.

Hirschi, M., Seneviratne, S. I., Alexandrov, V., Boberg, F., Boroneant, C., Christensen, O. B., Formayer, H., Orlowsky, B., and Stepanek, P.: Observational evidence for soil-moisture impact on hot extremes in southeastern Europe, Nat. Geosci., 4, 17-21, https://doi.org/10.1038/ngeo1032, 2011.

Hirschi, M., Meuller, B., Dorigo, W., and Seneviratne, S. I.: Using remotely sensed soil moisture for land-atmosphere coupling diagnostics: The role of surface vs. root-zone soil moisture variability, Remote Sens. Environ., 154, 246-252, https://doi.org/10.1016/j.rse.2014.08.030, 2014.

Koster, R., Schubert, S., and Suarez, M.: Analyzing the concurrence of meteorological droughts and warm periods, with implications for the determination of evaporative regime, J. Climate, 22, 3331-3341, https://doi.org/10.1175/2008JCLI2718.1, 2009.

Koster, R. D., Suarez, M. J., and Heiser, M.: Variance and Predictability of Precipitation at Seasonal-to-Interannual Timescales, J. Hydrol., 1, 26-46, https://doi.org/10.1175/15257541(2000)001<0026:VAPOPA>2.0.CO;2, 2000.

Koster, R. D., Dirmeyer, P. A., Guo, Z., Bonan, G., Chan, E., Cox, P., Gordon, C., Kanae, S., Kowalczyk, E., Lawrence, D., Liu, P., Lu, C.-H., Malyshev, S., McAvaney, B., Mitchell, K., Mocko, D., Oki, T., Oleson, K., Pitman, A., Sud, Y. C., Taylor, C. M., Verseghy, D., Vasic, R., Xue, Y., and Yamada, T.:: Regions of strong coupling between soil moisture and precipitation, Science, 305, 1138-1140, https://doi.org/10.1126/science.1100217, 2004.

Koster, R. D., Sud, Y. C., Guo, Z., Dirmeyer, P. A., Bonan, G., Oleson, K. W., Chan, E., Verseghy, D., Cox, P., Davies, H., Kowalczyk, E., Gordon, C. T., Kanae, S., Lawrence, D., Liu, P., Mocko, D., Lu, C.-H., Mitchell, K., Malyshev, S., McAvaney, B., Oki, T., Yamada, T., Pitman, A., Taylor, C. M., Vasic, R., and Xue, Y.: GLACE: The Global Land-Atmosphere Coupling Experiment. Part I: Overview, J. Hydrol., 7, 590-610, https://doi.org/10.1175/JHM510.1, 2006.

Koster, R. D., Mahanama, S. P. P., Yamada, T. J., Balsamo, G., Berg, A. A., Boisserie, M., Dirmeyer, P. A., Doblas-Reyes, F. J., Drewitt, G., Gordon, C. T., Guo, Z., Jeong, J.-H., Lawrence, D. M., Lee, W.-S., Li, Z., Luo, L., Malyshev, S., Merryfield, W. J., Seneviratne, S. I., Stanelle, T., van den Hurk, B. J. J. M., Vitart, F., and Wood, E. F.: Contribution of land surface initialization to subseasonal forecast skill: First results from a multi-model experiment, Geophys. Res. Lett., 37, L02402, https://doi.org/10.1029/2009GL041677, 2010.

Koster, R. D., Chang, Y., and Schubert, S. D.: A Mechanism for Land-Atmosphere Feedback Involving Planetary Wave Structures, J. Climate, 27, 9290-9301, https://doi.org/10.1175/JCLID-14-00315.1, 2014.

Lorenz, R., Pitman, A. J., Hirsch, A. L., and Srbinovsky, J.: Intraseasonal versus interannual measures of land-atmosphere coupling strength in a global climate model: GLACE-1 versus GLACECMIP5 experiments in ACCESS1.3b, J. Hydrol., 16, 2276-2295, https://doi.org/10.1175/JHM-D-14-0206.1, 2015.

Lorenz, R., Argüeso, D., Donat, M. G., Pitman, A. J., van den Hurk, B., Berg, A., Lawrence, D. M., Chéruy, F., Ducharne, A., Hagemann, S., Meier, A., Milly, P. C. D., and Seneviratne, S. I.: Influence of land-atmosphere feedbacks on temperature and precipitation extremes in the GLACECMIP5 ensemble, J. Geophys. Res.-Atmos., 121, 607-623, https://doi.org/10.1002/2015JD024053, 2016.

May, W., Meier, A., Rummukainen, M., Berg, A., Chéruy, F., and Hagemann, S.: Contributions of soil moisture interactions to climate change in the tropics in the GLACE-CMIP5 experiment, Clim. Dynam., 45, 3275-3297, https://doi.org/10.1007/s00382015-2538-9, 2015.

Miralles, D., den Berg, M. v., Teuling, A., and de Jeu, R.: Soil moisture-temperature coupling: A multiscale observational analysis, Geophys. Res. Lett., 39, L21707, https://doi.org/10.1029/2012GL053703, 2012.

Miralles, D. G., Teuling, A. J., van Heerwaarden, C. C., and de Arellano, J. V.-G.: Mega-heatwave temperatures due to combined soil desiccation and atmospheric heat accumulation, Nat. Geosci., 7, 345-349, https://doi.org/10.1038/ngeo2141, 2014.

Mueller, B. and Seneviratne, S. I.: Hot days induced by precipitation deficits at the global scale, P. Natl. Acad. Sci. USA, 109, 12398 12403, https://doi.org/10.1073/pnas.1204330109, 2012.

Riahi, K., Rao, S., Krey, V., Cho, C., Chirkov, V., Fischer, G., Kindermann, G., Nakicenovic, N., and Rafaj, P.: RCP 8.5 - A scenario of comparatively high greenhouse gas emissions, Climatic Change, 109, 33-57, https://doi.org/10.1007/s10584-011-0149y, 2011 .

Santanello, J. A., Peters-Lidard, C. D., and Kumar, S. V.: Diagnosing the Sensitivity of Local Land-Atmosphere Coupling via the Soil Moisture-Boundary Layer Interaction, J. Hydrol., 12, 766786, https://doi.org/10.1175/JHM-D-10-05014.1, 2011.

Santanello, J. A., Roundy, J., and Dirmeyer, P. A.: Quantifying the Land-Atmosphere Coupling Behavior in Modern Reanalysis Products over the U.S. Southern Great Plains, J. Climate, 28, 5813-5829, https://doi.org/10.1175/JCLI-D-14-00680.1, 2015.

Schwingshackl, C., Hirschi, M., and Seneviratne, S. I.: Quantifying Spatiotemporal Variations of Soil Moisture Control on Surface Energy Balance and Near-Surface Air Temperature, J. Climate, 30, 7105-7124, https://doi.org/10.1175/JCLI-D-160727.1, 2017.

Seneviratne, S. I., Lüthi, D., Litschi, M., and Schär, C.: Landatmosphere coupling and climate change in Europe, Nature, 443 205-209, https://doi.org/10.1038/nature05095, 2006.

Seneviratne, S. I., Corti, T., Davin, E. L., Hirschi, M., Jaeger, E. B., Lehner, I., Orlowsky, B., and Teuling, A. J.: Investigating soil moisture-climate interactions in a 
changing climate: A review, Earth-Sci. Rev., 99, 125-161, https://doi.org/10.1016/j.earscirev.2010.02.004, 2010.

Seneviratne, S. I., Nicholls, N., Easterling, D., Goodess, C. M., Kanae, S., Kossin, J., Luo, Y., Marengo, J., McInnes, K., Rahimi, M., Reichstein, M., Sorteberg, A., Vera, C., and Zhang, X.: Changes in Climate Extremes and their Impacts on the Natural Physical Environmenty, in: Managing the Risks of Extreme Events and Disasters to Advance Climate Change Adaptation. A Special Report of Working Groups I and II of the Intergovernmental Panel on Climate Change (IPCC), edited by: Field, C. B., Barros, V., Stocker, T. F., Qin, D., Dokken, D. J., Ebi, K. L., Mastrandrea, M. D., Mach, K. J., Plattner, G.-K., Allen, S. K., Tignor, M., and Midgley, P. M., 109-230, Cambridge University Press, Cambridge, UK and New York, NY, USA, 2012.

Seneviratne, S. I., Wilhelm, M., Stanelle, T., Hurk, B., Hagemann, S., Berg, A., Cheruy, F., Higgins, M. E., Meier, A., Brovkin, V., Claussen, M., Ducharne, A., Dufresne, J.-L., Findell, K. L., Ghattas, J., Lawrence, D. M., Malyshev, S., Rummukainen, M., and Smith, B.: Impact of soil moistureclimate feedbacks on CMIP5 projections: First results from the GLACE-CMIP5 experiment, Geophys. Res. Lett., 40, 52125217, https://doi.org/10.1002/grl.50956, 2013.

Seneviratne, S. I., Donat, M. G., Pitman, A. J., Knutti, R., and Wilby, R. L.: Allowable $\mathrm{CO}_{2}$ emissions based on regional and impact-related climate targets, Nature, 529, 477-483, https://doi.org/10.1038/nature16542, 2016.

Sippel, S., Zscheischler, J., Mahecha, M. D., Orth, R., Reichstein, M., Vogel, M., and Seneviratne, S. I.: Refining multi-model projections of temperature extremes by evaluation against landatmosphere coupling diagnostics, Earth Syst. Dynam., 8, 387403, https://doi.org/10.5194/esd-8-387-2017, 2017.

Taylor, K. E., Stouffer, R. J., and Meehl, G. A.: An overview of CMIP5 and the experiment design, B. Am. Meteorol. Soc., 93, 485-498, https://doi.org/10.1175/BAMS-D-11-00094.1, 2012.
Teuling, A., Hirschi, M., Ohmura, A., Wild, M., Reichstein, M., Ciais, P., Buchmann, N., Ammann, C., Montagnani, L., Richardson, A., Wohlfahrt, G., and Seneviratne, S. I.: A regional perspective on trends in continental evaporation, Geophys. Res. Lett., 36, L02404, https://doi.org/10.1029/2008GL036584, 2009.

van den Hurk, B., Best, M., Dirmeyer, P., Pitman, A., Polcher, J., and Santanello, J.: Acceleration of land surface model development over a decade of GLASS, B. Am. Meteorol. Soc., 92, 15931600, https://doi.org/10.1175/BAMS-D-11-00007.1, 2011.

Vogel, M. M., Orth, R., Cheruy, F., Hagemann, S., Lorenz, R., Hurk, B., and Seneviratne, S. I.: Regional amplification of projected changes in extreme temperatures strongly controlled by soil moisture-temperature feedbacks, Geophys. Res. Lett., 44, 1511-1519, https://doi.org/10.1002/2016GL071235, 2017.

World Climate Research Programme's Working Group on Coupled Modelling: Coupled Model Intercomparison Project 5 (CMIP5), available at: https://esgf-node.llnl.gov/search/cmip5, last access: 10 October 2018.

Whan, K., Zscheischler, J., Orth, R., Shongwe, M., Rahimi, M., Asare, E. O., and Seneviratne, S. I.: Impact Of Soil Moisture On Extreme Maximum Temperatures In Europe, Weather and Climate Extremes, 9, 57-67, https://doi.org/10.1016/j.wace.2015.05.001, 2015.

Wilks, D. S.: "The stippling shows statistically significant gridpoints": How Research Results are Routinely Overstated and Overinterpreted, and What to Do about It, B. Am. Meteorol. Soc., 97, 2263-2273, https://doi.org/10.1175/BAMS-D-15$00267.1,2016$.

Zscheischler, J., Orth, R., and Seneviratne, S. I.: A submonthly database for detecting changes in vegetationatmosphere coupling, Geophsy. Res. Lett., 42, 9816-9824, https://doi.org/10.1002/2015GL066563, 2015. 